\title{
A comparison of scavenging and deposition processes in global models: results from the WCRP Cambridge Workshop of 1995
}

By P. J. RASCH ${ }^{1 *}$, J. FEICHTER ${ }^{2}, \mathrm{~K}_{\text {LAW }}^{3}$, N. MAHOWALD ${ }^{4}$, J. PENNER ${ }^{5}$, C. BENKOVITZ ${ }^{6}$, C. GENTHON ${ }^{7}$, C. GIANNAKOPOULOS ${ }^{3}$, P. KASIBHATLA ${ }^{8}$, D. KOCH ${ }^{9}$, H. LEVY $^{10}$, T. MAKI ${ }^{11}$, M. PRATHER ${ }^{12}$, D. L. ROBERTS ${ }^{13}$, G.-J. ROELOFS ${ }^{14}$, D. STEVENSON ${ }^{13}$, Z. STOCKWELL $^{8}$, S. TAGUCHI ${ }^{15}$, M. KRITZ ${ }^{16}$, M. CHIPPERFIELD ${ }^{8}$, D. BALDOCCHI ${ }^{17}$, P. McMURRY ${ }^{18}$, L. BARRIE ${ }^{19}$, Y. BALKANSKI ${ }^{20}$, R. CHATFIELD ${ }^{16}$, E. KJELLSTROM ${ }^{21}$, M. LAWRENCE ${ }^{22}$, H. N. LEE $^{23}$, J. LELIEVELD ${ }^{14}$, K. J. NOONE ${ }^{21}$, J. SEINFELD ${ }^{22}$, G. STENCHIKOV ${ }^{24}$, S. SCHWARTZ ${ }^{6}$, C. WALCEK ${ }^{25}$, D. WILLIAMSON ${ }^{1}$, ${ }^{1}$ National Center for Atmospheric Research, PO Box 3000, Boulder CO, 80307, USA ${ }^{2}$ Max Planck Institute for Meteorology, Bundestrasse 55, D-20146 Hamburg, Germany; ${ }^{3}$ Centre for Atmospheric Science, Department of Chemistry, University of Cambridge, CB2 IEW, Cambridge, UK; ${ }^{4}$ Bren School of Environmental Science and Management, University of California, Santa Barbara, CA, 93106-5131, USA ${ }^{5}$ Atmospheric, Oceanic and Space Sciences, University of Michigan, Ann Arbor, MI, USA; ${ }^{6}$ Environmental Chem. Division, Brookhaven National Laboratory, Upton, NY 11973, USA; ${ }^{7}$ LGGE CNRS, F-38402, St Martin D'Heres Cedex, France; ${ }^{8}$ School of the Environment, Levine Science Research Center Duke University, Box 90328, Durham, NC 27708, USA; ${ }^{9}$ NASA GISS, 2880 Broadway, NY, NY 10025, USA; ${ }^{10}$ GFDL, Princeton, NJ, 08542-0308, USA; ${ }^{11} J M A$ 1-3-4 Otemachi, Chiyoda-ku Tokyo 100, Japan; ${ }^{12}$ Department of Earth System Science, University of California, Irvine, CA 92717-3100, USA; ${ }^{13}$ UK Meteorological Office, London Road, Bracknell, RG12 2SY, UK; ${ }^{14} I M A U$, Utrecht University, Princetonplein 5, 3584 CC Utrecht, NL; ${ }^{15}$ NIRE, 16-3, Onogawa, Tsukuba, Ibaraki, 305, Japan; ${ }^{16} \mathrm{MSRC}$, SUNY Albany, PO Box 468, NY; ${ }^{17}$ ATDD NOAA, Oak Ridge, TN, 37831, USA; ${ }^{18}$ University of Minnesota, Minneapolis, MINN 55455, USA; ${ }^{19}$ AES Downsview, ONT, Canada M3H 5T4; ${ }^{20}$ LMCE, CEA-DSM, 91191 Gif-Yvette, France; ${ }^{21}$ MISU, S-106 91 Stockholm, Sweden; ${ }^{22}$ MPI for Chemistry, 55122 Mainz, Germany; ${ }^{23}$ EML USDOE NY, NY10014-35621, USA; ${ }^{24}$ University of Maryland, College Park, MD 20742, USA; ${ }^{25}$ ASRC-SUN Y Albany, NY 12205, USA.

(Manuscript received 17 November 1998; in final form 15 December 1999)

\section{ABSTRACT}

We report on results from a World Climate Research Program workshop on representations of scavenging and deposition processes in global transport models of the atmosphere. 15 models were evaluated by comparing simulations of radon, lead, sulfur dioxide, and sulfate against each other, and against observations of these constituents. This paper provides a survey on the simulation differences between models. It identifies circumstances where models are consistent with observations or with each other, and where they differ from observations or with each other. The comparison shows that most models are able to simulate seasonal species concentrations near the surface over continental sites to within a factor of 2 over many regions of the globe. Models tend to agree more closely over source (continental) regions than for remote (polar and oceanic) regions. Model simulations differ most strongly in the upper troposphere for species undergoing wet scavenging processes. There are not a sufficient number of observations to characterize the climatology (long-term average) of species undergoing wet scavenging in the upper troposphere. This highlights the need for either a different strategy for model evaluation (e.g., comparisons on an event by event basis) or many more observations of a few carefully chosen constituents.

\footnotetext{
* Corresponding author.

e-mail: pjr@ucar.edu
}

Tellus 52B (2000), 4 


\section{Introduction}

\subsection{Motivation for the model intercomparison}

Wet and dry deposition processes are important mechanisms in the control of both the temporal and spatial distributions of many gaseous and particulate trace species in the atmosphere.These species in turn influence the chemistry and climate of the atmosphere, and the underlying ocean and biosphere. The component processes labelled by the general terms "wet" and "dry" deposition are extremely complex, and span many subdisciplines of meteorology, physics and chemistry. These processes are important, and difficult to represent in a reasonable way in models purporting to simulate the distribution of atmospheric trace species, and their impacts and feedbacks on the earth's climate.

The representation of these processes in global chemical transport and general circulation models have traditionally been crude. In the last 10 years progress has been made in the understanding of these component processes, both from a theoretical and an observational point of view, with a corresponding increase in the complexity and realism of model representations of these processes. It is not been clear however, what the impact of these differences in representation of deposition processes has had on trace species distributions. In August of 1995 the World Climate Research Programme (WCRP) sponsored a workshop on the role of scavenging and dry deposition processes on the control of trace gases in global models, at Downing College in Cambridge, UK. It was the third WCRP workshop in a series dealing with the modelling of trace constituents by global models. The first in 1990 (Pyle and Prather, 1996) focused on the global-scale transport of long lived trace species by resolved transport. The second meeting in 1993 (Jacob et al., 1997; Boville et al. 1997) brought into focus the transport by subgridscale processes.

About 60 scientists from 11 countries attended the workshop from 3 areas: (1) theoreticians and process modellers working on detailed and explicit representations of deposition process and the cloud physics important in understanding the transport, scavenging and chemistry taking place within clouds; (2) physical climate modellers and chemists wanting to perform global simulation of trace species; (3) scientists specializing in atmo- spheric observations and able/interested in contributing to the validation of a modelling effort. The meeting was intended to provide opportunities to identify the state of the art in modelling, to identify the range of uncertainties in our understanding of processes, and to estimate our ability to model those processes. Part of the meeting consisted of an intercomparison of the simulations of short-lived atmospheric tracers by 15 global models, and their comparison to relevant observations.

Results from this intercomparison are summarized here. It is not the intent of this paper to identify the right or wrong way of modelling a given deposition process. To do so would require very constrained simulations that would fix all aspects of the simulation except one and explore variations on only one parameterization. Such a study is impossible in the context of a large intercomparison with many different models. Rather, it was the intent of the meeting, and this paper, to survey the field, identifying the ways in which parameterization of these processes differ between models, then compare their simulations with observations and each other, looking for similarities and differences in the simulation. It was hoped that the similarities and differences would reveal areas of systematic bias between model and observations, or systematic agreement. The areas of bias might point toward processes requiring more work. Those areas where the models agree with each other and observations identify aspects of the simulation where models may be more easily trusted.

The modellers were asked to perform 2 simulations, with a number of minor variations (described in more detail below). Most models attempted only a subset of the complete specification of the test problems. The first problem was to model the emission of ${ }^{222}$ radon, its transport and decay to ${ }^{210}$ lead, attachment to an aerosol, and subsequent removal by dry deposition and scavenging processes. The second problem was to compare corresponding loss processes for $\mathrm{SO}_{2}$ and $\mathrm{SO}_{4}^{2-}$ (hereafter sulfate) which we refer to as the $\mathrm{SO}_{x}$ problem. Because of its relatively simple source and sink, radon has long been recognized as a useful tracer of convective and synoptic-scale motions in global models. The radon/lead problem provided a means to examine the role of both the transport of a short-lived species, and its sub- 
sequent scavenging by wet and dry deposition processes. The $\mathrm{SO}_{x}$ simulation expanded the comparison to include the scavenging of gas phase constituents and gas and aqueous chemistry in a system with very different source characteristics from that of the radon. The $\mathrm{SO}_{x}$ problem is a widely studied system with relevance to acid rain and climate. A wide variety of models (listed in Table 1) participated in the workshop.

\subsection{Some comments on scavenging and deposition in global models}

While a detailed discussion of the physics of these processes is beyond the scope of this paper, we begin by briefly stating the physics associated with wet and dry deposition of atmospheric species, which form the basic path by which trace species are removed from the atmosphere. More detail on these processes can be found in the text by Seinfeld and Pandis (1997), although that text does not focus on the additional complexities of representation of the processes in large-scale modelling environments. The participating models span the spectrum of means to represent these processes and the resulting simulations reflect this fact. For this reason, we have attempted to focus on general properties of all the simulations and avoid a focus on an explicit evaluation of particular models.

Dry deposition. We define dry deposition as the mechanisms by which gaseous and particulate species are transferred from the atmosphere onto surfaces in the absence of precipitation. Dry deposition occurs on a variety of length and time scales. On the largest scales the tracers are transported towards the surface by turbulence and organized circulation features and by gravitational settling. As the trace specie (molecule or particle) approaches to within a few millimeters of a surface air motions become small, and molecular and brownian diffusive motions become important. The trace specie may then interact with the surface in a variety of ways. Gaseous species may absorb reversibly or irreversibly, or react chemically with the surface. Aerosols particles can collide with the surface through inertia, and either bounce off, or adhere, depending on the properties of the aerosol and the surface. Dry deposition depends upon the individual properties of the turbulent transfer, the molecular and brownian diffusion of the tracer, the resistance of the tracer to uptake by the surface itself, and, for aerosol particles, the sedimentation velocity which in turn depends on the size, mass, and shape of the particle. The deposition thus depends upon turbulent properties in the atmosphere, chemical composition and roughness of the surface, inhomogenieties in the surface, and properties of the molecule or particle itself. These properties vary on space scales from tens of meters at the large end to molecular length scales at the small end, and these features must be included in some fashion in global models, whose smallest spatial resolution is typically hundreds of $\mathrm{km}$ in

Table 1. Model participants; a list of acronyms may be found in Section 7

\begin{tabular}{lccl}
\hline \multicolumn{1}{c}{ Model } & Institute & Radon/lead & ${\text { Simple } \mathrm{SO}_{x}}^{\text {Full SO }_{x}}$ \\
\hline ECHAM3 & MPI Hamburg & $\mathrm{Rn} / \mathrm{Pb}$ & \\
ECHAM4 & MPI Hamburg & $\mathrm{Rn} / \mathrm{Pb}$ & \\
ECWAG & U. Wageningen & $\mathrm{Rn} / \mathrm{Pb}$ & \\
GFDL & GFDL & $\mathrm{Rn} / \mathrm{Pb}$ & \\
GISSHIY & GISS/Harvard/ & $\mathrm{Rn} / \mathrm{Pb}$ & $\mathrm{X}$ \\
& UCIrving/Yale & $\mathrm{Xn} / \mathrm{Pb}$ & \\
GRANTOUR/ECHAM & LLNL/U. Michigan & $\mathrm{Rn} / \mathrm{Pb}$ & \\
LGGE/LMD & LGGE & $\mathrm{Rn}$ & \\
MUTM & Monash Univ. & $\mathrm{Rn}$ & \\
MATCH & NCAR & $\mathrm{Rn} / \mathrm{Pb}$ & $\mathrm{X}$ \\
TOMCAT & U. Cambridge & $\mathrm{Rn} / \mathrm{Pb}$ & $\mathrm{X}$ \\
CCM $\Omega$ & NCAR & $\mathrm{Rn} / \mathrm{Pb}$ & $\mathrm{X}$ \\
STOCHEM & UKMO & $\mathrm{Rn} / \mathrm{Pb}$ & $\mathrm{X}$ \\
TRA95 & JMA & & \\
Uni. Mod. & UKMO & $\mathrm{Rn} / \mathrm{Pb}$ & \\
NIRE & NIRE & & \\
\hline
\end{tabular}

Tellus 52B (2000), 4 
the horizontal, and hundreds of meters in the vertical. Clearly all the important processes occur on length scales much smaller than that of the model resolution, and much of the important character of the process must be parameterized, that is, be represented in a statistical sense, rather than by some explicit description arising from a physical development from first principles. Dry deposition today is almost uniformly modelled by assuming the surface deposition flux is proportional to a concentration times a "deposition velocity". The complexity of course comes in the specification of the deposition velocity. The simplest representations for dry deposition prescribe a fixed deposition velocity that depends upon the species, and land surface type More complicated models use so-called "resistance in series" deposition formulations (Wesely, 1989), which represent this processes using an electrical resistance analogy where the transport of material is assumed to be governed by 3 or 4 resistances in series (an aerodynamic, quasi-laminar, surface, and sedimentation resistance respectively). These resistances can depend upon such things as solar insolation, land use, vegetation type, surface wetness, etc. Both types of dry deposition models were represented in this workshop. Some modellers prescribed a single deposition velocity for each constituent. Others used much more complex resistance in series approaches. We note the deposition type for each model in Table 7.

Wet deposition. Wet deposition, the removal of a soluble trace species by transfer associated with precipitation, is equally difficult to represent in global models. The soluble species is first assumed to find a path from the air into a cloud or rain drop. When the condensed water is subsequently deposited at the ground, it will carry some of the soluble species with it. We note that if the raindrop evaporates before reaching the ground then it will act as an internal transport mechanism, even if the soluble specie is not removed from the atmosphere itself. One usually distinguishes between "in-cloud" and "below cloud" scavenging. In-cloud scavenging refers to a local removal process in which the initial deposition of the species is within a small cloud drop, which subsequently undergoes growth through collision or coalescence to a size identified as a raindrop. The soluble matter that was initially in the cloud condensate, and sub- sequently removed as precipitate, undergoes "in-cloud" scavenging (also termed rainout). On the other hand, as the precipitate falls, it can also collect soluble species directly from interstitial air ("below cloud" scavenging or washout). Soluble species can get into the condensate in a variety of ways. Many aerosols act as cloud condensation nuclei. That is, water vapour condenses preferentially on soluble or wettable particles to form cloud drops subsequently removed via in-cloud scavenging. Aerosols can also be taken up directly on falling precipitate through a number of collection mechanisms. Larger aerosols are taken up by collision associated with their inertia. Smaller particles are collected by Brownian motion. Soluble gases are taken up in both smaller cloud drops and larger raindrops following Henry's Law (and thus are sensitive to $\mathrm{pH}$ and temperature of the drops), where they can undergo chemical transformation, or be removed along with the condensate. Clearly, wet deposition is intimately tied up with the cloud microphysics itself. A realistic description of the scavenging process thus requires a knowledge of the microphysics of the condensation and precipitation (i.e., distribution of the condensate and precipitate, the sources responsible for the generation of the condensate, the conversion from condensate to precipitate), and the microphysics of the aerosol. There are also a number of additional complications peculiar to large-scale models, where all cloud processes are subgridscale. Because the clouds are not resolved at the grid length scale, they occupy only part of a volume. One must then consider mechanisms for exchange of mass between the cloud and its environment (all within a single grid volume), the fact that the volume encountering precipitation is not the same as the local cloud volume, the spatial distribution of the clouds within a column, and the ways in which the condensate and precipitate overlap with each other within that column. Again, a broad spectrum of approaches have been adopted by modelling groups. In the simplest formulations, wet removal is parameterized in terms of a first order loss rate, that is, the sink of a tracer is made proportionate to a mixing ratio times a coefficient, with the coefficient a function of the gridbox averaged precipitation flux.

Some models (e.g., GISSHIY and ECHAM) have a relatively long history of attempting to simulate these processes. For others this was the 
first time that they had attempted simulations of short-lived soluble species. There is a broad range of variation in the representation of scavenging in these models. Some models (like TOMCAT), without access to much information about cloud processes, attempted to model the wet removal based only on the relative humidity in the model atmosphere, and assumptions about the frequency of rain in each model volume. Others, like the UKMO model, did not distinguish between in-cloud and below cloud scavenging, or between liquid and ice processes, or between scavenging of gases and aerosols. The more mature models attempted to integrate their removal processes in an entirely consistent manner with their hydrologic cycle, and make much stronger distinctions between these processes using a more elaborate formulation. For example, the NCAR and ECHAM model use information from the model's representations for the hydrological cycle to distinguish between the scavenging of gases and the aerosol scavenging, where incloud scavenging is made proportionate to the amount of condensate that is converted to precipitate, and the below cloud scavenging is again presumed to be proportionate to the precipitation flux within a layer. Care is also taken to scavenge only within the volume of air where cloud or rain is present, and assumptions must be made about the rate at which air is exchanged between cloudy and cloud-free air.

\section{Description of model experiments}

\subsection{The radon/lead simulations}

${ }^{222}$ Radon is a noble gas with a source in the continental crust (arising from the decay of uranium daughter species) and a sink from radioactive decay with an e-folding time scale of 5.5 days. The source of radon is approximately 1.0 atoms $/ \mathrm{cm}^{2} / \mathrm{s}$ from unfrozen continents (Jacob and Prather, 1990), with an uncertainty of a factor of 2 locally (Turekian, 1977). The source from oceanic regions and ice-covered regions are approximately 2 orders of magnitude less than the land source. Participants were asked to use a source distribution of 1.0 atoms $\mathrm{cm}^{-2} \mathrm{~s}^{-1}$ over land between $60 \mathrm{~S}$ and $60 \mathrm{~N}$, and 0.5 atoms $\mathrm{cm}^{-2} \mathrm{~s}^{-1}$ over land between $60^{\circ} \mathrm{N}$ to $70^{\circ} \mathrm{N}$, except Greenland, where the surface was assumed to be ice-covered. The simulation provides an opportunity to assess the ability of the model to simulate the evolution of a relatively short-lived tracer, strongly influenced by boundary layer turbulent transport, convection, synoptic scale transport, and after conversion to lead, its removal by wet and dry deposition processes on soluble aerosols. Comparison with observations for radon were made at a variety of continental and remote sites around the world, at the seasonal and monthly time scales. Modellers were asked to run their models for 3 months to allow the radon and lead distributions to spin up, and then integrate for a 1-year period. Tabulated results of seasonal and annually averaged burdens, as well as wet (below and in-cloud) and dry scavenging rates were requested from each participant. Latitude-longitude figures for the lowest model level, $600 \mathrm{hPa}$, and $300 \mathrm{hPa}$ for January, July and annual means for radon were requested. A latitude longitude figure of instantaneous values at $300 \mathrm{hPa}$ for 1 July was requested to provide information about the general amplitude of model departures from the above mean values. Latitude height cross-sections for January, July and annual means for radon, lead, lead production and scavenging rates were also requested for zonal averages, and at $180^{\circ} \mathrm{W}$ and $27^{\circ} \mathrm{E}$ to provide information on the 3-dimensional distributions of these species. The contour interval, units and figure dimensions were all specified to facilitate the model intercomparison.

The distribution of radon in both observations and model simulations results reflects its continental origins. Surface distributions of radon are discussed in some detail in Jacob et al. (1997) and the general distributions seen in our study did not differ significantly. As the product of radon's radioactive decay, lead surface concentration patterns are similar. Mixing-ratios are high over the continents, in particular over dry regions like the Sahara and Arabia where little wet removal occurs. Continental annual mean mixing-ratios in all the model simulations range between 250 and $2000 \mathrm{mBq}$ per cubic meter of air at standard temperature and pressure (hereafter called SCM for Standard Cubic Meter). Over the oceans values are between 100 and $1 \mathrm{mBq} / \mathrm{SCM}$ with lowest values over Antarctica ( $<25 \mathrm{mBq} / \mathrm{SCM})$. Most of the models show concentrations over the US between 500 and $1000 \mathrm{mBq} / \mathrm{SCM}$ with values exceeding $1000 \mathrm{mBq} / \mathrm{SCM}$ over the Sahara, Arabia and south-west Asia. Simulated deposition 
fluxes on the $\mathrm{NH}$ mid-latitudes are in the range between 50 and $250 \mathrm{~Bq} \mathrm{~m} \mathrm{yr}^{-1}$. All models show the highest fluxes $\left(250-500 \mathrm{~Bq} \mathrm{~m}^{-2} \mathrm{yr}^{-1}\right)$ in the Monsoon regions. Deposition fluxes over marine areas south of $30^{\circ} \mathrm{S}$ were between 1 and $25 \mathrm{~Bq} \mathrm{~m} \mathrm{mr}^{-1}$. While the distribution of the surface concentration of lead is quite smooth and differences in the horizontal model resolution cannot be recognized, the patterns of the deposition fluxes are patchy and clearly reflected the model resolution.

\subsection{The $\mathrm{SO}_{x}$ simulations}

Two $\mathrm{SO}_{x}$ experiments were defined. In both experiments, only the anthropogenic emissions from $\mathrm{SO}_{2}$ were requested, although some participants also included the biogenic sources. Seasonally and spatially varying anthropogenic $\mathrm{SO}_{2}$ sources representative of 1985 were provided from the IGAC/GEIA data base (Benkovitz et al., 1996), with a global annual average of about $65 \mathrm{Tg} \mathrm{S} / \mathrm{yr}$. In the first experiment, called the "simple $\mathrm{SO}_{x}$ experiment", participants were asked to convert $\mathrm{SO}_{2}$ to $\mathrm{SO}_{4}^{2-}$ with a 1.2-day lifetime and to use their model specified dry and wet deposition formulations for removal. In the second experiment, called the "full chemistry experiment", each participant used their best model formulation for the transformation of $\mathrm{SO}_{2}$ to $\mathrm{SO}_{4}^{2-}$. The simple experiment allowed those groups without an explicit photochemical mechanism for the transformation to participate. Also, by comparing simple to full photochemical simulation one could evaluate the impact of the photochemistry with localized sources and sinks for species that depended upon sunlight, cloud water, cloud volume, precipitation rates, etc., with a simpler formulation. Unfortunately, only one participant contributed to both experiments. Two of the participants in the simple experiment included full emissions (natural and anthropogenic). The models were evaluated by comparison between each other (in terms of surface concentrations, vertical profiles, dry and wet deposition rates, and $\mathrm{SO}_{4}^{2-}$ production rates) and through a comparison with observations. As in the radon/lead comparison, figures of latitude/ height and latitude/longitude cross-sections using a common set of contours, units, and dimensions for $\mathrm{SO}_{2}, \mathrm{SO}_{4}^{2-}$, and their production and loss mechanisms were requested from each modelling group. The largest emissions occur in the northern hemisphere over Central Europe, Asia, and the Eastern US (ordered from highest to lowest emissions). This is reflected in the surface distribution of both $\mathrm{SO}_{2}$, and $\mathrm{SO}_{4}^{2-}$. While the values of $\mathrm{SO}_{2}$ were relatively consistent between models over the source regions (see below discussion), they differ substantially in remote regions. For example, while the ECHAM model has $\mathrm{SO}_{2}$ values below $1 \mathrm{~kg} / \mathrm{SCM}$ of air southward of $60^{\circ} \mathrm{S}$, TOMCAT (which included a DMS emission source) generally showed values between 20 and $50 \mathrm{~kg} / \mathrm{SCM}$ there. Similar differences between models were also seen in the northern hemisphere polar regions. The differences in $\mathrm{SO}_{4}^{2-}$ between models in remote regions were also very large. Model differences are discussed in more detail below.

\section{Strategy of model evaluation}

The intent of the evaluation was to identify similarities and differences between the spatial and temporal properties of the models and observations. The observations are comprised of individual measurements taken at a specific time and place. It is worthwhile to discuss the principle problems of such a comparison. With multiple observations one can average to provide a mean value representative of a region or time period. Some of the observations used in this intercomparison were for periods as brief as 1 year. Other data spanned a 20-year time period. Because of spatial and temporal inhomogenieties in both the radon and $\mathrm{SO}_{x}$ species there can be substantial differences in measurements between adjacent stations on short spatial scales. Because global models have quite a coarse spatial and temporal resolution, and because none of the models used meteorology specific to the particular time period of the observations, we avoid comparison between model and observations on a day-by-day basis. Rather, we focus on regional and seasonal (concentration) or annual (deposition) averages. For most individual measurements, particularly in source regions, we have tended to consider them in toto. Regions were chosen where observations showed similar seasonality and magnitude. Some sites which did not meet these conditions were removed. Observations from remote islands were considered to be representative of a much larger area and 
therefore often compared directly to the model results. Because this study considered constituents with a strong continental source, distributions there are dominated by those sources; surface concentrations over the continents reflect mainly the source strength and the vertical exchange within the PBL. We think remote sites are a much better indicator of whether transport and scavenging performs well, because remote receptor sites are controlled primarily by vertical and horizontal transport and by removal processes. This assumption will not hold if mesoscale circulations are important at a particular site.

There are also sampling issues to consider. Offline transport models are driven by model generated wind fields, some of which have been constrained by observed winds (i.e., forecast centre analyses). Others are produced from a general circulation model (GCM). In order to produce climatological mean concentrations and reduce the role of inter-annual variability, a model should be integrated for several years and the ensemble average compared to the observations. The participating models reported results from a single 1-year simulation. Different meteorological fields drove each tracer simulations, which resulted in different spatial and temporal distributions even if the same model physics were used. Therefore, the impact on the species distribution of different approaches for transport and scavenging could not be separated from use of a different meteorology. Lastly we note that models differed in their treatment of short timescale features. GCMs (e.g., ECHAM, and the NCAR CCM $\Omega$ ) model the transport, chemistry and removal of chemical species at every time step of their integration, and resolve features with time scales of order $1 \mathrm{~h}$. The diurnal cycle, and the episodic nature of convection, scavenging and aqueous chemistry are captured in these models. All off-line models used 4to 12-hourly input fields to drive their constituent evolution. Their diurnal cycle and episodic processes were less well resolved (although it is not clear the 4-6-hourly averaged field are not sufficient to approximately resolve these features (Rasch et al., 1997)). Also the different horizontal and vertical resolution of the models have an impact on the calculated species distributions. Since we have assumed a constant exhalation rate for ${ }^{222} \mathrm{Rn}$ some discrepancies between observations and simulations may also be due to temporal and spatial variations of the radon sources (Jacob and Prather, 1990). Assuming a seasonally invariant radon source introduces a seasonal bias in the radon and lead simulation. Mid-latitude surface measurements show a surpression of radon emission by soil freezing in winter. There are also spring to fall differences in radon emissions that might have to do with water logging of the soil.

Jacob et al. (1997) reported on a similar intercomparison (taking place in 1993) of radon simulations where about half the participating models were deemed "under development". Because the processes controlling the radon representation are central to the models ability to simulate lead, we provide an update on those findings as well as highlighting results from more recent observations.

Unfortunately, long-term measurements of ${ }^{210}$ lead (and with many other constituents) are available only as surface concentrations and deposition rates. Deposition rates are determined by collecting precipitation over a long period of time or by using natural collectors like snow fields, lake sediments and soil cores. Thus deposition rates are not able to resolve seasonal fluxes. We therefore compared the observations to model annual means only. Deposition data compilations from Feichter et al. (1991) and Preiss et al. (1996) were used, as were concentrations of lead in surface air measured by EML (Environmental Measurements Laboratory, US) since 1957 at about 115 sites worldwide, mostly in the US (Lee and Feichter, 1995). These data were provided as monthly means (R. Larsen, personal communication). We also used data compiled in Feichter et al. (1991) and Balkanski et al. (1993). The observational estimates for the $\mathrm{SO}_{x}$ comparison from EMEFS (McNaughton and Vet, 1996) and EMEP data (Schaug et al., 1987). The EMEFS and EMEP datasets were composited using the strategy outlined in Kasibhatla et al. (1997).

\section{Model results}

\subsection{Global properties}

We begin by describing the models' globally integrated properties. None of the species entering in the comparison are sufficiently well characterized by observations to provide credible observational estimates of global burdens, but a global 
metric still provides information about differences in model processes. Because emissions and sinks were assumed constant, the models show no seasonal cycle of their global radon burdens. The global burden of lead is controlled by differences in the hydrologic cycle. Seasonal changes in convection over source regions can lift the radon to heights where subsequent scavenging as lead is inefficient. Seasonal changes in precipitation processes and location will also change the efficiency of scavenging. The $\mathrm{SO}_{x}$ cycle is strongly controlled by these same processes, as well as by variations in the emissions, and by seasonal variations in the oxidant distributions controlling the transformation of $\mathrm{SO}_{2}$ to $\mathrm{SO}_{4}$.

Global annually averaged lead burdens, and residence times are shown in Table 2. Lead burdens range over a factor of 3 over all models, but agreement is much closer (within $30 \%$ of the ensemble mean) when the outliers are not considered (GRANTOUR, NIRE and TRA95). Radon emissions should total $1.25 \mathrm{~kg}$ radon/month (equivalent to $1.18 \mathrm{~kg}$ lead$/ \mathrm{month}$ ).

Departures of the sum of the wet and dry deposition from this value may be due to the models not being at steady state, or some nonconservative aspect to the models. The residence time (defined as the burden divided by deposition) varies between 3 and 10 days, The GCM simulations reported lifetimes of 6 to 8 days. Offline models reported a much wider range of residence times. Estimates based on observations vary from 6.5 days (Lambert et al., 1982) to 8-10 days (Moore et al. (1973), Balkanski et al. (1993)), but these numbers are still quite uncertain due to the sparsity of observations (Balkanski et al., 1993). The ratio of dry to wet deposition, which measures the relative importance of the 2 processes in removal of the aerosol varies from less than $10 \%$ for most models, to about $50 \%$ in outliers implying important differences in those model formulations.

Seasonal variation in the global burdens of lead are plotted in Fig. 1a. Most models show a maxima during the northern hemisphere summertime, with a small seasonal variation. The higher burdens in summer are often attributed to more rapid venting of the planetary boundary layer, or convective lofting of radon and lead itself to heights where the aerosol is not susceptible to either dry deposition or wet scavenging. The wet deposition of lead is shown in Fig. 1b. There is a marked difference in the seasonal cycle in the ECHAM3 and ECHAM4 models. This may in part be due to changes in turbulent transport by the PBL scheme between the models and the associated changes in the precipitation over land.

Fig. 1b indicates that there is little seasonal variation in the deposition. Analysis of the precipitation dataset of Legates and Willmot (1990) shows a small seasonal variation in the average precipitation over land with a maximum and minimum respectively of about 2.5 and $2.1 \mathrm{~mm} /$ day during NH summer and winter. The seasonal cycle of the global burden and the precipitation are not mirrored in the wet deposition rates themselves. Lofting of radon and aerosols will generate an opposite seasonal cycle to scavenging in the immediate vicinity of the emission region. The lack of a seasonal cycle in deposition and the maxima in the seasonal cycle in the lead

Table 2. Global characterization of lead (annual average, $N / A=$ not available)

\begin{tabular}{lccccc}
\hline \multicolumn{1}{c}{ Model } & $\begin{array}{c}\text { Burden } \\
(\mathrm{kg})\end{array}$ & $\begin{array}{c}\text { Dry dep } \\
(\mathrm{kg} / \text { month })\end{array}$ & $\begin{array}{c}\text { Wet dep } \\
(\mathrm{kg} / \text { month })\end{array}$ & $\begin{array}{c}\text { Total dep } \\
(\mathrm{kg} / \mathrm{month})\end{array}$ & $\begin{array}{c}\text { Residence } \\
\text { time (days) }\end{array}$ \\
\hline ECHAM3 & 0.29 & 0.09 & 1.17 & 1.28 & 6.8 \\
ECHAM4 & 0.23 & 0.11 & 0.91 & 1.02 & 6.8 \\
ECWAG & 0.23 & 0.18 & 1.02 & 1.20 & 5.8 \\
GFDL & 0.23 & $\mathrm{~N} / \mathrm{A}$ & $\mathrm{N} / \mathrm{A}$ & $\mathrm{N} / \mathrm{A}$ & 5.8 \\
CCM $\Omega$ & 0.32 & 0.11 & 1.07 & 1.18 & 8.1 \\
LGGE & 0.24 & 0.10 & 1.24 & 1.36 & 5.9 \\
GRANTOUR/ECHAM & 0.15 & 0.18 & 0.99 & 1.17 & 3.8 \\
GISSHIY & 0.30 & 0.11 & 1.06 & 1.17 & 9.1 \\
NIRE & 0.13 & 0.09 & 1.2 & 1.29 & 3.2 \\
TOMCAT & 0.32 & 0.07 & 1.1 & 1.20 & 8.3 \\
TRA95 & 0.44 & 0.40 & 0.86 & 1.30 & 10.6 \\
\hline
\end{tabular}



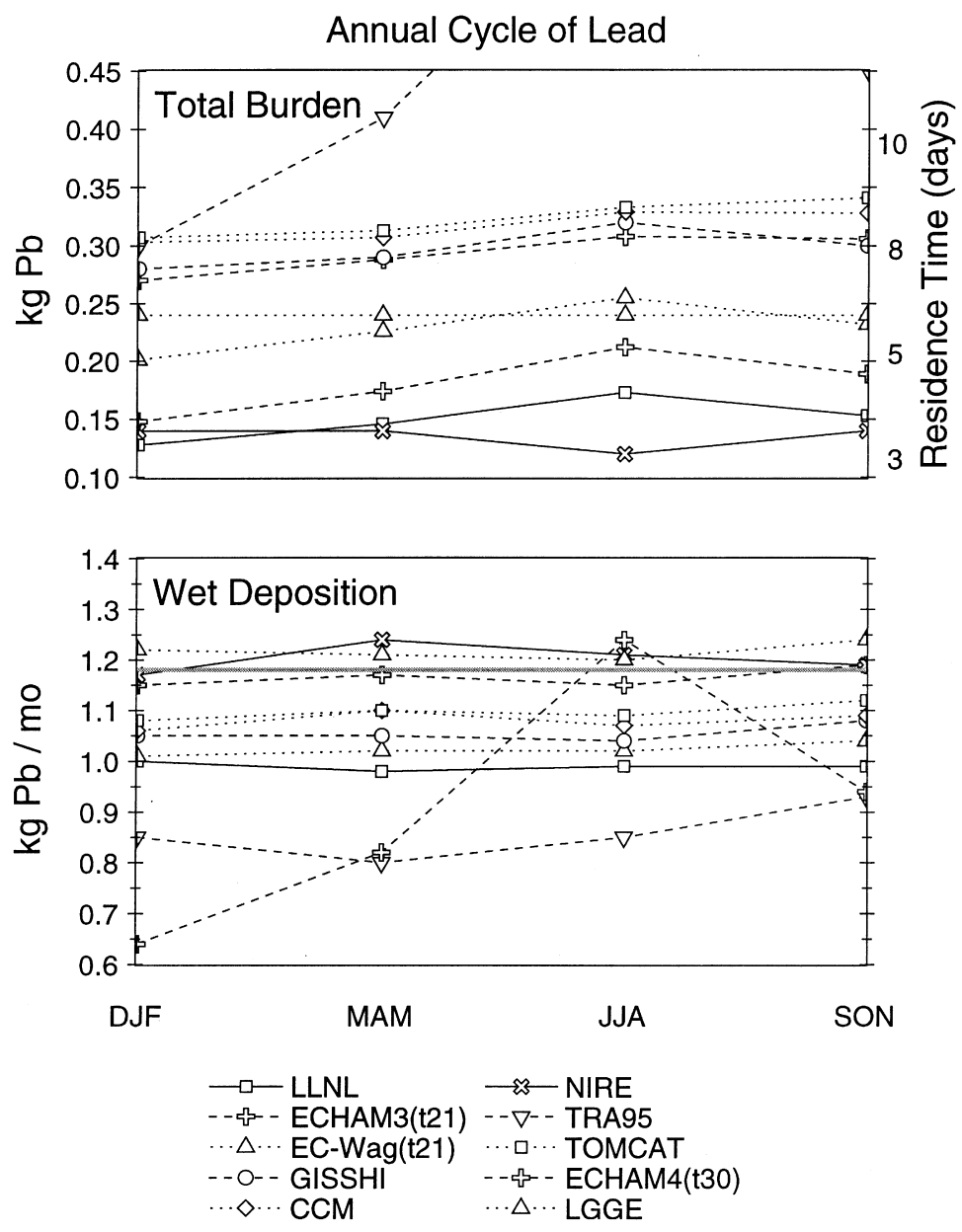

Fig. 1. Seasonal evolution of the burden of lead (upper panel) and wet deposition (lower panel) for each model. The heavy grey line in the lower panel at $1.18 \mathrm{~kg} / \mathrm{month}$ shows the prescribed production rate for lead due to the decay of radon.

burden suggest that lofting modulates the residence time in the atmosphere more strongly than variations in scavenging processes.

Globally averaged $\mathrm{SO}_{2}$ and $\mathrm{SO}_{4}$ burdens are shown in Tables 3 and 4, respectively. $\mathrm{SO}_{2}$ burdens vary by a factor of 4 , although the variation within the cluster of models using simple or full chemistry is much smaller. The variation in $\mathrm{SO}_{4}$ is larger than that of $\mathrm{SO}_{2}$, and similar to the lead simulation variation. The model with the most efficient deposition of lead is not the same as the model with the most efficient deposition of $\mathrm{SO}_{x}$. Total deposition of $\mathrm{SO}_{2}$ and $\mathrm{SO}_{4}$ should again balance emissions. Those models (NIRE, TOMCAT and
TRA95) that do not sum to about $65 \mathrm{Tg} \mathrm{S} / \mathrm{yr}$ also included the DMS emissions. Replenishment/ removal time scales (defined as the global burden divided by the process global source or sink) for $\mathrm{SO}_{2}$ and $\mathrm{SO}_{4}$ appear within the parentheses in the tables. Full chemistry models show higher $\mathrm{SO}_{2}$ burdens than most of the simple chemistry models, suggesting that the conversion rate in the simple chemistry experiment was set to be considerably too rapid for a close match to the full chemistry simulation. The departure from 1.2 days in chemical conversion time scales for some simple chemistry models (the number in parentheses in the rightmost column) indicates inconsistencies in 
Table 3. $\mathrm{SO}_{2}$ global annually averaged statistics; timescales (defined as global burden divided by global tendency) for a particular process are shown in parentheses

\begin{tabular}{|c|c|c|c|c|c|c|}
\hline $\begin{array}{c}\text { Model } \\
\text { (* has DMS } \\
\text { emissions) }\end{array}$ & $\begin{array}{l}\text { Full or } \\
\text { simple }\end{array}$ & $\begin{array}{l}\text { Burden } \\
\text { (Tg S) } \\
\text { (res time } \\
\text { days) }\end{array}$ & $\begin{array}{c}\text { Dry dep } \\
\text { (Tg S/yr) }\end{array}$ & $\begin{array}{l}\text { Wet dep } \\
(\mathrm{Tg} \mathrm{S} / \mathrm{yr})\end{array}$ & $\begin{array}{l}\text { Total dep } \\
(\mathrm{Tg} \mathrm{S} / \mathrm{yr})\end{array}$ & $\begin{array}{l}\text { Chem loss } \\
\text { (Tg S/yr) }\end{array}$ \\
\hline ECHAM3 & $\mathrm{F}$ & $0.24(1 \cdot 3)$ & $25(3.3)$ & $3.6(24)$ & $29(3.6)$ & $37(2.4)$ \\
\hline GFDL & $\mathrm{F}$ & $0.31(1.7)$ & $23(4.9)$ & $15(7.5)$ & $38(3.0)$ & $27(4.2)$ \\
\hline GISSHIY & $\mathrm{F}$ & $0.20(1.1)$ & $23(3.2)$ & $13(5.6)$ & $36(2.0)$ & $30(2.4)$ \\
\hline $\mathrm{CCM} \Omega$ & $\mathrm{F}$ & 0.34 (1.9) & $22(5.6)$ & $1.1(113)$ & $23(5.4)$ & $42(3.0)$ \\
\hline $\mathrm{CCM} \Omega$ & $\mathrm{S}$ & $0.14(0.8)$ & $16(3.2)$ & $7.5(6.8)$ & $23(1.5)$ & $42(1.2)$ \\
\hline NIRE* & $\mathrm{S}$ & $0.20(1.1)$ & $5.6(13)$ & $45(1.6)$ & $51(1.5)$ & $31(2.4)$ \\
\hline TOMCAT* & $\mathrm{S}$ & $0.10(0.55)$ & $32(1.1)$ & $19(1.9)$ & $50(0.73)$ & $31(1.2)$ \\
\hline TRA95* & $\mathrm{S}$ & $0.083(0.36)$ & $56(0.54)$ & $12(2.5)$ & $68(0.45)$ & $16(1.9)$ \\
\hline UKMO & $\mathrm{S}$ & $0.11(0.61)$ & $14(2.9)$ & $20(2.0)$ & $34(1.2)$ & $31(1.3)$ \\
\hline
\end{tabular}

Table 4. Global annual average $\mathrm{SO}_{4}^{2-}$ (models labelled with $a *$ also include a DMS source)

\begin{tabular}{lccccc}
\hline \multicolumn{1}{c}{ Model } & $\begin{array}{c}\text { Full or } \\
\text { simple }\end{array}$ & $\begin{array}{c}\text { Burden } \\
(\text { Tg S })\end{array}$ & $\begin{array}{c}\text { Dry dep } \\
\text { (Tg S/yr) }\end{array}$ & $\begin{array}{c}\text { Wet dep } \\
\text { (Tg S/yr) }\end{array}$ & $\begin{array}{c}\text { Total dep } \\
(\text { Tg S/yr) }\end{array}$ \\
\hline ECHAM3 & F & 0.39 & $5.8(24)$ & $32(4.4)$ & $38(3.8)$ \\
GFDL & F & 0.22 & $3.5(23)$ & $25(3.2)$ & $29(2.8)$ \\
GISSHIY & F & 0.39 & $4.6(31)$ & $25(5.7)$ & $30(4.9)$ \\
CCM $\Omega$ & F & 0.39 & $3.1(46)$ & $37(3.5)$ & $44(3.2)$ \\
CCM $\Omega$ & $\mathrm{S}$ & 0.47 & $5.3(32)$ & $28(2.6)$ & $42(4.1)$ \\
NIRE* & $\mathrm{S}$ & 0.21 & $3.2(21)$ & $27(3.9)$ & $31(2.5)$ \\
TOMCAT* & $\mathrm{S}$ & 0.29 & $5.0(21)$ & $6.9(9.0)$ & $33(3.2)$ \\
TRA95 & $\mathrm{S}$ & 0.17 & $10(8.8)$ & $24(3.6)$ & $15(4.1)$ \\
UKMO & $\mathrm{S}$ & 0.24 & & $34(2.6)$ \\
\hline
\end{tabular}

their simulation. Dry deposition plays a much more important role for $\mathrm{SO}_{2}$ than it does for lead. The ratio of dry to wet deposition for $\mathrm{SO}_{2}$ is very large. The large discrepancy in wet deposition rates may be due to the way in which sulfur compounds are labelled as they are deposited at the surface. Some model included only S(IV) in the wet deposition of $\mathrm{SO}_{2}$; others included both the deposition of $\mathrm{S}(\mathrm{IV})$ and $\mathrm{S}(\mathrm{VI})$. Total wet deposition of sulfur species (which avoid this ambiguity) are much closer than either component. It is interesting to see that the 2-model participants with full chemistry which had published results from their simulation (ECHAM (Feichter et al., 1996) and GISSHIY (Chin and Jacob, 1996)), and were presumably the most mature of the models in terms of their development for this purpose still differ in the partitioning of dry and wet deposition.

Global burdens of $\mathrm{SO}_{4}^{2-}$ (Table 4) also show large differences, varying by a factor of 3 between models. Wet deposition tends to dominate dry, and the range of variation in $\mathrm{SO}_{4}^{2-}$ is large. It is quite surprising that in spite of the large differences in $\mathrm{SO}_{2}$ burdens, and the production rates of $\mathrm{SO}_{4}^{2-}$ (the chemical loss of $\mathrm{SO}_{2}$ ), most of the full chemistry models (except GFDL) reach a similar total burden of $\mathrm{SO}_{4}^{2-}$. We regard this agreement as fortuitous. The very large differences in $\mathrm{SO}_{4}^{2-}$ burden and deposition processes in the simple chemistry simulations suggest that there remain substantial variations in the way transport and deposition processes are represented in global models, even in the absence of resolved chemistry.

The seasonal cycles of $\mathrm{SO}_{2}$ and $\mathrm{SO}_{4}$ are shown in Fig. 2 for participating models. Most models show a minimum in $\mathrm{SO}_{2}$ during the northern hemisphere summer when $\mathrm{SO}_{4}^{2-}$ is at a maximum. There is a small $(<\sim 20 \%)$ seasonal variation in the emissions dataset used in this study with the largest temporal variation in winter over Europe. 

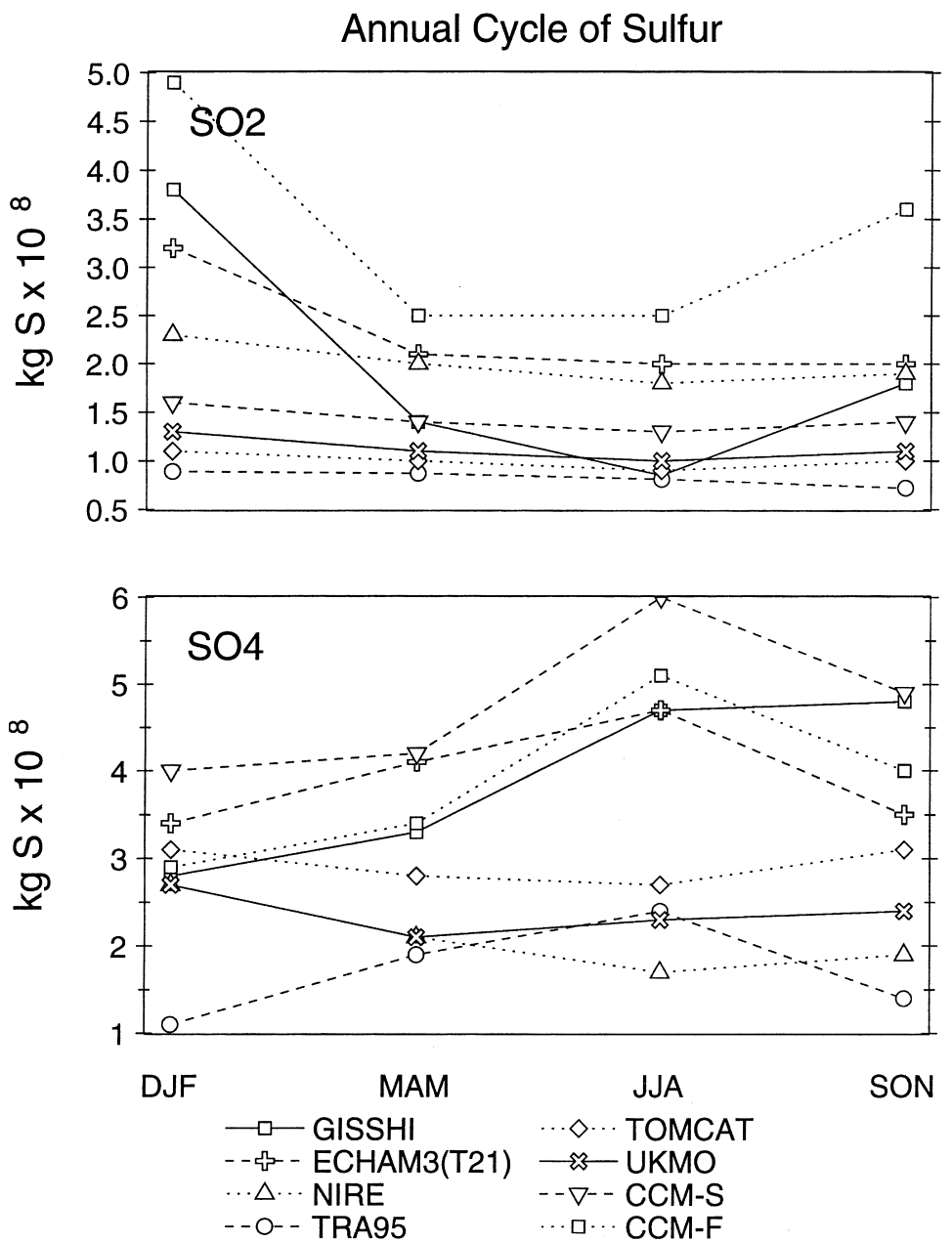

Fig. 2. Seasonal evolution of burden of $\mathrm{SO}_{2}$ (upper panel) and $\mathrm{SO}_{4}^{2-}$ (lower panel) for each model. The suffix "-S" and "-F" on the CCM model indicate the runs with "simple" or "full" chemistry respectively. See text for details.

The larger variations seen in the $\mathrm{SO}_{2}$ and $\mathrm{SO}_{4}^{2-}$ signature are not therefore due to emission variations, but rather to a combination of the seasonal variation in oxidants, volume of air processed (both from oxidation and scavenging) by clouds, and lofting to altitudes where the deposition processes are not effective. The seasonal cycle in those models with "full" chemistry tend to be larger than the simple sulfur cycle models. The simple sulfur models are not sensitive to oxidant amount (and therefore to large variations in production terms), but still show large variation in $\mathrm{SO}_{2}$ and sulfate burden. This summertime maximum was also seen in the lead simulation, and suggests that the "lofting mechanism" is a common and important control on aerosol lifetime. The variation in production terms and loss must also be important in the controlling the seasonal aerosol burden variation, but we cannot identify their relative importance from the reported information.

4.1.1. Zonal means. Fig. 3 shows annually and zonally averaged distributions for 2 representative models as an indication of the range of variation in simulations of radon, lead, sulfur dioxide and sulfate. Note that there is an approximately logarithmic variation in the contour levels for each species. Therefore small differences in the contours 

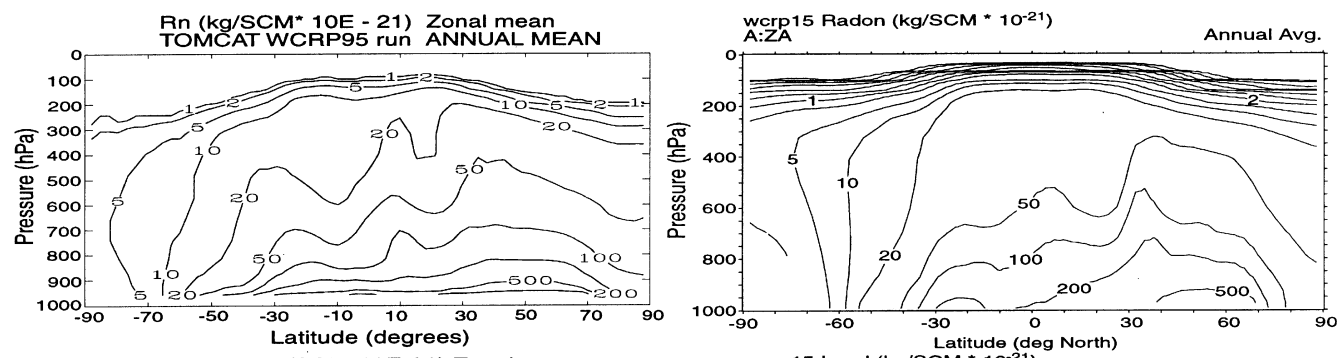

PB-210 (kg/SCM*10E-21) Zonal mean

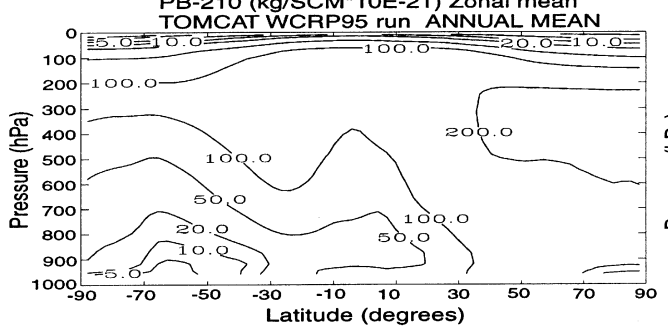

$\underset{A: Z A}{\text { wcrp } 15 \text { Lead }\left(\mathrm{kg} / \mathrm{SCM}^{*} 10^{-21}\right)}$
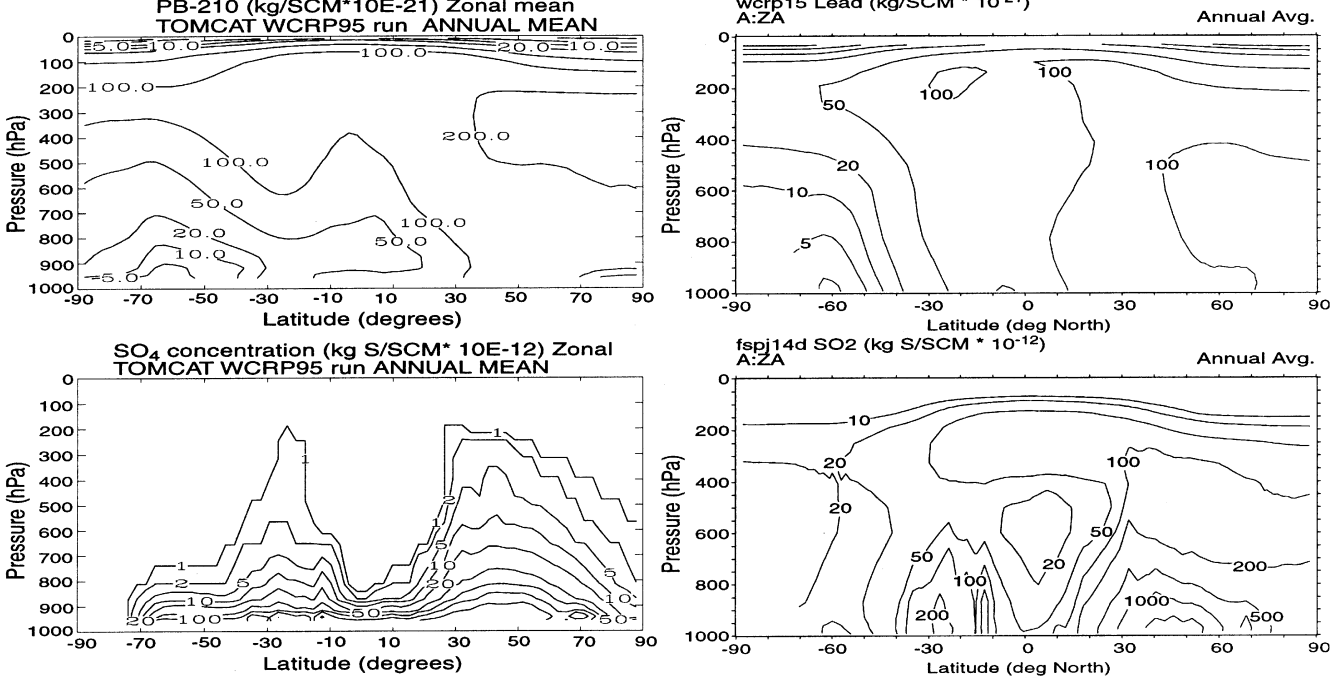

fspij 14d SO2 (kg S/SCM*10 $\left.10^{-12}\right)$

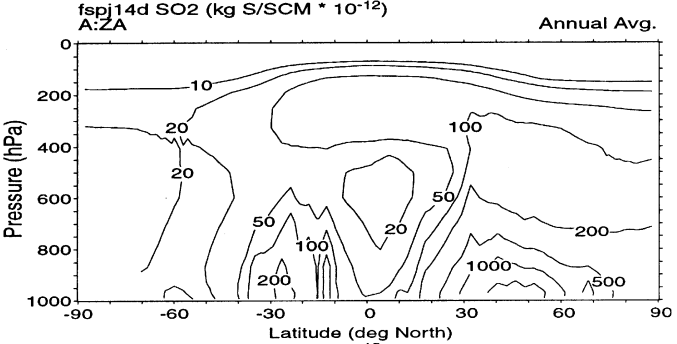

$\mathrm{SO}_{4}$ concentration (kg S/SCM* 10E-12) Zonal
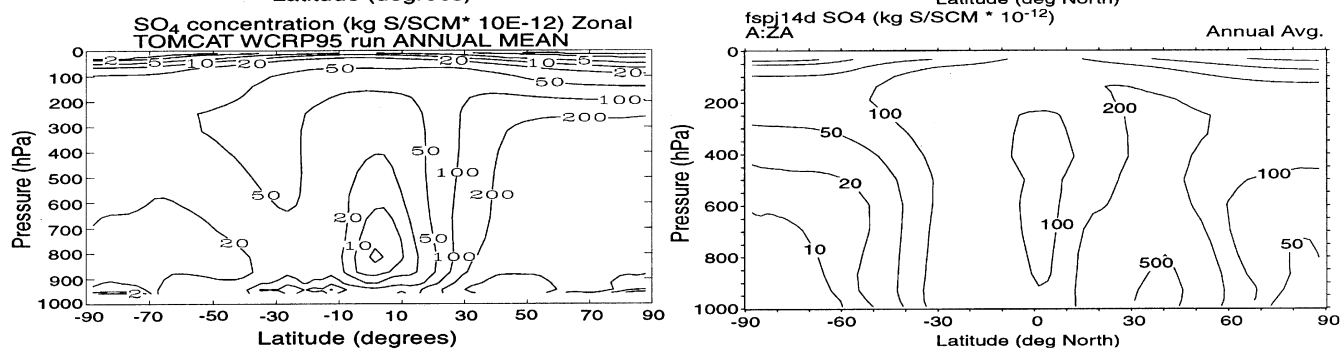

Fig. 3. Annually averaged, zonal average distribution of radon, lead, $\mathrm{SO}_{2}$ and $\mathrm{SO}_{4}^{2-}$, ordered from top to bottom respectively. Left column shows results from a simulation by the TOMCAT model. Right panel shows the simulations by the NCAR CCM-F model. The units are $\mathrm{kg} / \mathrm{SCM} \times 10^{-21}$. Contours are spaced approximately logarithmically at $(1,2,5) \times 10^{n}$, where $n$ is some integer.

can imply factor of 2 differences in the simulation. The departure of model outliers is substantially larger than is seen in these example models. Vertical distributions of radon were generally similar in the lower troposphere, with much larger discrepancies evident in the upper troposphere and in polar regions. In the upper tropospheric subsidence region of the Hadley cell some models (GISSHIY, MATCH, MUTM, NIRE, ECHAM4) showed almost no evidence of subsidence, while others showed substantial penetration of subsidence into the mid-lower troposphere. Evidence for differences in the way moist convective mixing is treated in the different models was seen in the zonal mean vertical distribution of radon in the tropics. Some models calculated a localised maximum in the upper tropical troposphere (UKMO, GISSHIY, MATCH-EC, MATCH-NMC, 
MUTM). Other models' radon concentrations decreased more uniformly with altitude. This localised maxima most likely results from varying intensities and vertical redistribution profiles used by the convective parameterizations in the various models. These features were discussed in more detail in Jacob et al. (1997).

Substantial differences in radon were also evident in northern polar regions. For example, LMD, $\mathrm{CCM} \Omega$, GISSHIY, MUTM, NIRE models show very low concentrations in this region. Unfortunately, observations were not available for comparison prior to the workshop, so we were unable to identify which models more accurately simulated the transport in the Arctic regions. But subsequent work on the LMD and GISSHIY models by Preiss and Genthon (1997) suggest that the low concentrations in many models could be attributed to biases in the model circulation (e.g., an inability to represent strong surface inversions which inhibit transfer from the free troposphere to the surface layer, or to a lack of horizontal wave transport from mid-latitudes into these regions) or in the numerical methods used.

The differences between models were even larger in constituents undergoing wet scavenging. Most models show a maximum in the zonal mean lead mixing ratios in the lower troposphere over the source regions. Generally there are 2 types of models in terms of their behaviour in the PBL. Some have a well mixed PBL (ECHAM3, CCM $\Omega$, LGGE, GISSHIY) and others show an increase with height with a maximum at the top of the PBL (ECWAG4, ECHAM3, NIRE). Since models with the same transport scheme showed different vertical profiles (e.g., ECWAG3 and ECHAM3), this may be due to a different treatment of below cloud scavenging. In the free troposphere many of the models show a decrease in mixing-ratio by about one order of magnitude between the PBL and $400 \mathrm{hPa}$ and a weaker gradient above. Some models show a mid-tropospheric minimum with an increase in lead mixing ratios above (e.g., Fig. 3, TOMCAT), with mixing-ratios at $100 \mathrm{hPa}$ as high as at the surface. This may be attributed to the efficient upward transport of radon into the upper troposphere. Scavenging in many of these models is not efficient at high altitudes. For example, TOMCAT parameterizes the scavenging rate as proportional to the relative humidity, so scavenging is highest within the PBL and less inefficient in the middle troposphere, where the relative humidity is often lower. The concentrations at $100 \mathrm{hPa}$ differ between models by 1 order of magnitude, with values as high as $200 \times 10^{-21} \mathrm{~kg} / \mathrm{kg}$ simulated by GISSHIY, and $100 \times 10^{-21} \mathrm{~kg} / \mathrm{kg}$ by TOMCAT, and as low as $20 \times 10^{-21} \mathrm{~kg} / \mathrm{kg}$ by the ECHAM models. The zonal mean vertical distribution is quite different between the south and north polar regions. Over Antarctica all models show an increase in concentrations with height due to poleward transport from lower latitudes. Two models also show slightly higher values near the South-Pole than at the edge of Antarctica (e.g., TOMCAT, Fig. 3) due to subsidence from the upper troposphere. Very small vertical gradients above the PBL were seen in the northern polar regions in all the models. The ECHAM models, ECHWAG, NIRE and TOMCAT showed a slight increase in concentration above the PBL.

Two maxima generally appeared in the vertical distribution of the lead scavenging rate (not shown) one in the NH mid-latitudes and one in the tropics. Most models show the mid-latitude maximum within the PBL. The maximum in the tropics varied strongly from model to model. Some simulated it close to the surface (LGGE, NIRE and TOMCAT). In other models, this maxima occurred much higher up (at $800 \mathrm{hPa}$ by ECWAG3, at $700 \mathrm{hPa}$ by ECHAM3, at $600 \mathrm{hPa}$ by $\mathrm{CCM} \Omega$, at $300 \mathrm{hPa}$ by $\mathrm{MATCH}$ and at $200 \mathrm{hPa}$ by GISSHIY). GISSHIY shows also a uniform scavenging rate in the NH mid-latitudes between 900 and $250 \mathrm{hPa}$. ECWAG simulate also a secondary maximum at the surface in the tropics, likely due to below-cloud scavenging.

The zonally averaged distribution for sulfur species are shown in the lower panels of Fig. 3. The notable differences in that figure in $\mathrm{SO}_{2}$ distributions arise because TOMCAT used the simple sulfur cycle formulation, and the CCM simulation showed used a full chemistry formulation. The differences are characteristic of any comparison of models using the simple and full chemistry mechanisms for conversion of $\mathrm{SO}_{2}$ to $\mathrm{SO}_{4}^{2-}$. The CCM simulation using the simple sulfur chemistry looks very similar to that of TOMCAT (not shown).

A tongue of high $\mathrm{SO}_{2}$ air extends into the southern hemisphere in the upper troposphere in the CCM simulation indicating a path for inter- 
hemispheric transport of sulfur in this and other models with full chemistry. The higher values seen in the upper troposphere and southern hemisphere in the full chemistry models are due to the slower oxidation in the more realistic model formulations. It might be thought the more rapid oxidation of $\mathrm{SO}_{2}$ by the simple sulfur cycle would lead to higher $\mathrm{SO}_{4}^{2-}$ burdens in the simple models. This is clearly not the case for the TOMCAT and CCM models. The CCM model has substantially higher $\mathrm{SO}_{4}^{2-}$ burdens in the upper troposphere, emphasizing the importance of a consideration of the scavenging processes in the control of the aerosol as well as the production mechanism. As with the lead simulations, the range of variation in upper tropospheric loading of $\mathrm{SO}_{4}^{2-}$ varies strongly between models (by as much as one order of magnitude between outliers).

\subsection{Comparison with observations}

As discussed in the section on strategy, we have partitioned the globe into a number of areas where it is possible to compare the distributions with observations. The method of comparison differs for each trace species, but has been structured to exploit the observational data available.

4.2.1. Continental source regions. Radon. Many conclusions here for surface continental sites are quite similar to those of Jacob et al. (1997). Over the northern hemisphere continental region, surface observations were available at Cincinnati (49N, 84W) (Lambert, personal communication) and Socorro (34N, 107W) (Wilkening et al., 1975). Models identified as "established" in the 1992 WCRP (Jacob et al., 1997) showed agreement to within a factor of 2 at Cincinnati during the summer months. Most new models also agree well except for TOMCAT which used a local mixing scheme (Louis, 1979) for the boundary layer turbulence that may not vent the boundary layer rapidly enough. Models generally underpredicted the measured surface values at Cincinnati. This bias would be made worse if afternoon averages had been used (as was done in Jacob et al. (1997)) because radon concentrations are lowest at this time of day (Fisenne, 1985; Thom et al., 1993). We note that future intercomparisons may want to look at the diurnal cycle of radon predicted by models as we suspect major differences there between models and observations. Models are able to predict the seasonal cycle of radon at Cincinnati with a minima in May-June which is in good agreement with available observations. As mentioned earlier, the seasonal variation of surface radon is controlled in part by changing emission from soil freezing and water logging. These processes were not included in the emission scenario, and therefore the model/observation agreement in seasonal variation may be fortuitous. radon observations at Socorro show a winter maximum, which is consistent with a lower boundary layer height in the colder seasons. Half the models were able to capture this seasonal cycle. Overall, the models overpredict daily averaged concentrations at Socorro by $20 \%$ to $100 \%$. As with Cincinnati, this could be due to the fact that the observations were made at 2 p.m. local time, at which time the boundary layer has the highest height, and observed concentrations are lowest. The model biases at Cincinnati and Socorro are thus opposite of each other. Apart from differences in the treatment of PBL mixing, it is possible that higher emissions in this region could also account for this rather systematic difference.

Lead. Our conclusions on the simulation of lead are based on the surface observations summarized in Table 5. The table shows the region considered, number of measurement sites, and regionally averaged surface concentration and deposition fluxes. (N.B. Some sites report only annual mean surface concentrations. Where regions contained some stations reporting seasonal values, and some stations reporting annual mean values, the annual means may deviate from the mean value derived from the seasonal concentrations.) The comparison to model values was calculated by averaging over model grid-points corresponding to the same regions. A series of metrics were constructed to summarize the models' behaviour compared to the observations. For those interested in detail, metrics for each model appear are described in Table B1 of Appendix B of Rasch (1999). We summarize the model behaviour inferred from the table here.

The evaluation was made using 3 metrics for each station, error in surface concentration, error in surface deposition rate, and error in seasonality. The seasonality and surface concentration were normalized as a relative bias metric ( $\mathrm{RB})$ defined as $(m-o) /(m+o)$ with $o$ denoting the observations 
Table 5. Observations used for the lead comparison with model results (Larsen, Environmental Measurements Laboratory, US (personal communication); (Feichter et al., 1991); (Balkanski et al., 1993); (Preiss et al., 1996); seasonality $=(\max -\min ) /(\max +\min )$ based on the seasonal surface concentrations

\begin{tabular}{|c|c|c|c|c|c|c|c|c|c|}
\hline \multirow[b]{2}{*}{ Regions } & \multicolumn{6}{|c|}{ Mixing-ratio in $\mu \mathrm{Bq} / \mathrm{SCM}$} & \multirow[b]{2}{*}{ Seasonality } & \multicolumn{2}{|c|}{$\begin{array}{l}\text { Deposition } \\
\text { in } \mathrm{Bq} / \mathrm{m}^{2} / \mathrm{yr}\end{array}$} \\
\hline & $\begin{array}{l}\text { No. of } \\
\text { sites }\end{array}$ & DJF & MAM & JJA & SON & Annual & & $\begin{array}{l}\text { No. of } \\
\text { sites }\end{array}$ & Annual \\
\hline Greenland & 4 & 418 & 395 & 95 & 269 & 267 & 0.63 & 5 & 11 \\
\hline Antarctica & 4 & 48 & 28 & 43 & 46 & 29 & 0.26 & 2 & 1 \\
\hline east-USA & 4 & 572 & 452 & 473 & 623 & 533 & 0.16 & 15 & 176 \\
\hline central-USA & - & & & & & & & 20 & 140 \\
\hline $\begin{array}{l}\text { west-USA } \\
\text { west coast of }\end{array}$ & 13 & 679 & 339 & 341 & 571 & 486 & 0.35 & 3 & 140 \\
\hline South-America & 4 & 255 & 436 & 431 & 245 & 354 & 0.28 & - & \\
\hline Europe & 7 & & & & & 300 & & 29 & 107 \\
\hline India & 7 & & & & & 827 & & 8 & 144 \\
\hline $\begin{array}{l}\text { Japan and north- } \\
\text { west Pacific }\end{array}$ & - & & & & & & & 12 & 269 \\
\hline New Zealand & - & & & & & 166 & & $\begin{array}{c}21 \\
5\end{array}$ & 48 \\
\hline
\end{tabular}

and $m$ the model results. Note that the values of -0.33 and +0.33 denote factor of 2 differences between model and observations. The seasonality was defined as the corresponding bias between the amplitude of maximum and minimum (again normalized by the sum of the 2 numbers). Note that this metric says nothing about the phase of the cycle, except that when the seasonality was opposite to the observed signal reported in Table 5 the seasonality was assigned a negative value. We considered absolute values for $\mathrm{RB}$ of $<0.2$ as denoting "good" agreement; that between 0.20 and 0.33 (implying a model and observation are within a factor of 2) as "acceptable", and that larger than 0.33 as denoting "bad" agreement.

Agreement was good for most models over the USA, Europe, India and Australia and New Zealand for both surface concentrations and deposition fluxes. Agreement was acceptable over the west coast of South America and over Japan. Over the United States, where the observation density is highest, about $2 / 3$ of the models were within $50 \%$ of the observed surface concentrations with a tendency to underestimate the annual mean concentrations.

The seasonality over the US is not very well captured by most models. For example, Fig. 4 shows the seasonal evolution of surface concentra- tion for the Eastern US. Most models show the correct seasonality, with a maximum in fall/winter. Many models differ by $20-50 \%$ from the observations (shown in the heavy black line). We have not attempted to quantify variability in the observations in terms of precision, accuracy or year-toyear variability. There is also real uncertainty in the year-to-year variability of the model results, and this could not be assessed because only 15 -month runs were requested for model simulations. Winter concentrations were underpredicted, particularly over the western US, where even the best performing model was low by about $40 \%$. Summer concentrations were slightly overpredicted. The radon simulations showed an underprediction in winter and summer in Socorro, suggesting that the excessive lead concentrations in summer may be due to insufficient scavenging. The underestimate of the winter concentrations might be attributed to a too strong vertical exchange in the stable PBL or to a too coarse vertical resolution which cannot resolve winter inversion layers. The scatter between the models is highest in fall.

The annual mean deposition fluxes are generally in good agreement with the observations; but most of the models overestimate fluxes over the eastern and central US and underestimate them over the 


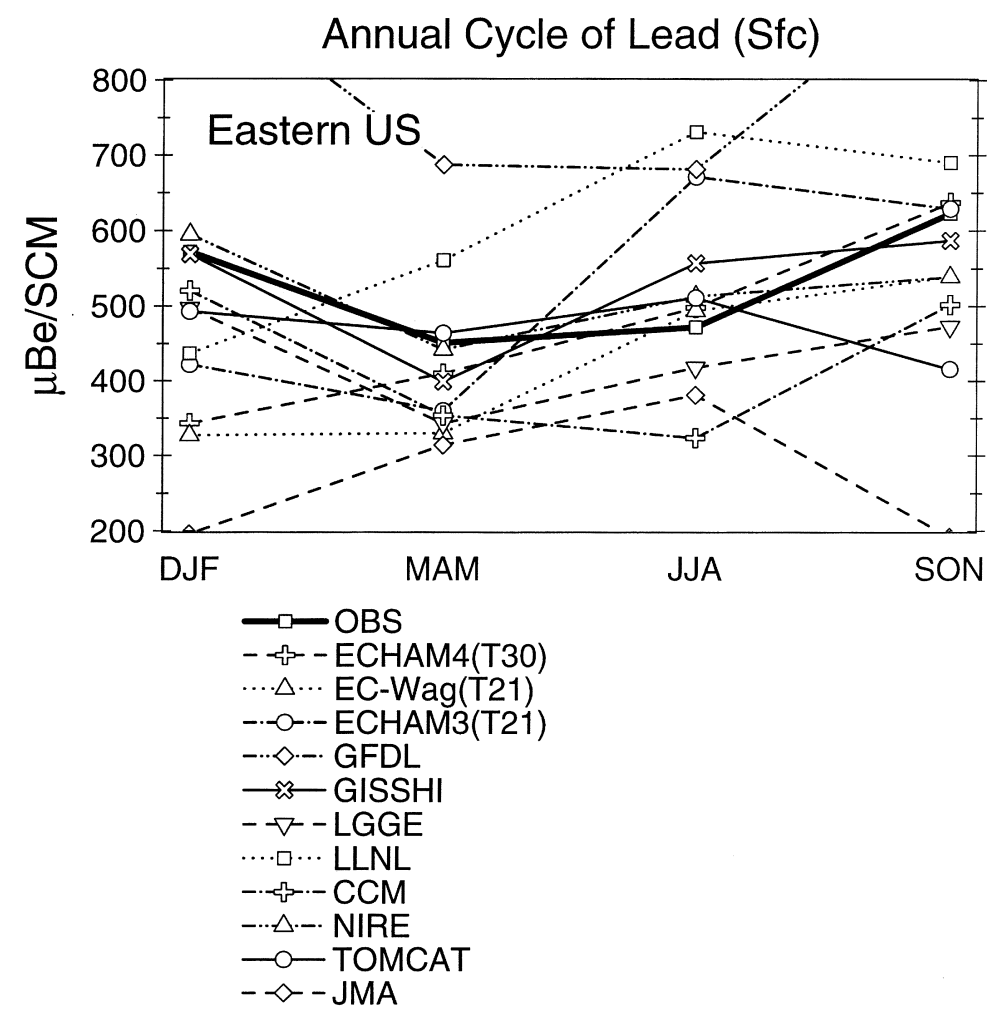

Fig. 4. The seasonal cycle of lead over the eastern US for the models (various thin line patterns) and the observational estimate (as the heavy black line).

western US in spite of the fact that the annual mean fluxes in the western US are lower (by a factor of 2 compared to the eastern and central US). At the west coast of South America only $50 \%$ of the models are in good agreement with observed concentrations, perhaps due to difficulties in resolving the land-sea contrast. Here, in contrast to North America, the models capture the seasonal cycle quite well. Annual mean concentrations are also in good agreement with observations over Europe and India. There is a tendency to simulate slightly higher than observed values over these regions even though concentrations over India are the largest seen in any of the areas being compared. Nearly all modelled deposition fluxes agree fairly well with observations over Europe, India and Australia and New Zealand whereas over Japan and the north-west Pacific islands all models fail to reproduce the very high observed deposition fluxes.

$\mathrm{SO}_{x}$. To compare surface measurements of $\mathrm{SO}_{2}$ and $\mathrm{SO}_{4}^{2-}$ to model results, we followed the compositing and analysis technique of Kasibhatla et al. (1997) and used the EMEP (Schaug et al., 1987) and EMEFS (McNaughton and Vet, 1996) data for January and July. The former dataset covers the period 1973-1992 at 61 sites over Europe. (We note emissions have changed greatly over this time period in this region with a corresponding impact on $\mathrm{SO}_{x}$ distributions.) The EMEFS measurements were made during 1988 to 1990 over North America. An example from the comparison is shown in Fig. 5, which displays the monthly mean average value for 6 models plotted against the corresponding observational estimate for $\mathrm{SO}_{2}$ and $\mathrm{SO}_{4}^{2-}$ during January over the 2 regions. Four of the models (CCM $\Omega$, GISSHIY, ECHAM4 and GFDL) included a "full chemistry" representation. The other 2 (TOMCAT and NIRE) used the simpler "simple chemistry" formulation. $\mathrm{SO}_{2}$ monthly mean concentrations varied by a factor of 15 over each regions. We believe 
A

$\mathrm{SO}_{2}$ January US (EMEFS)

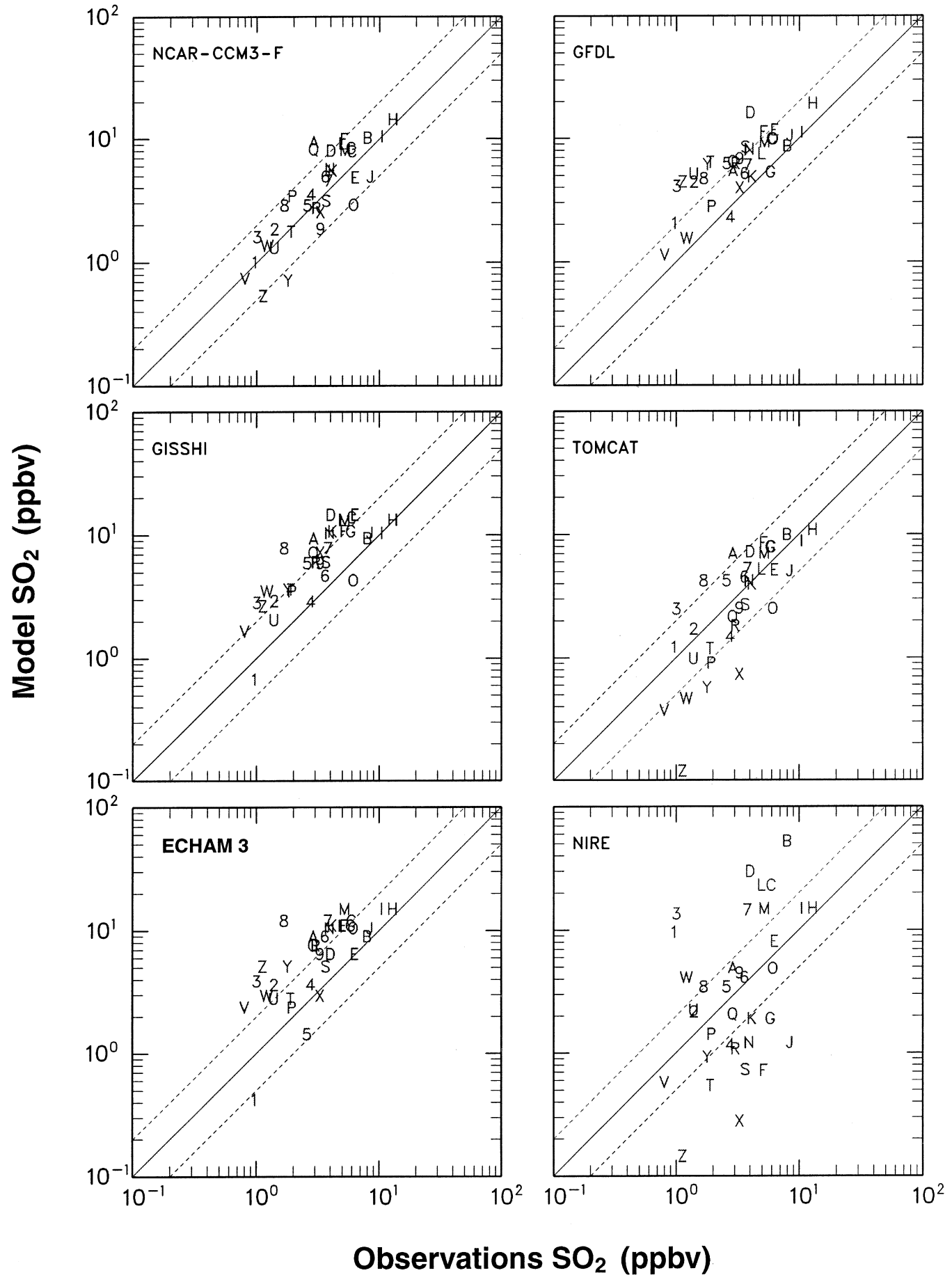




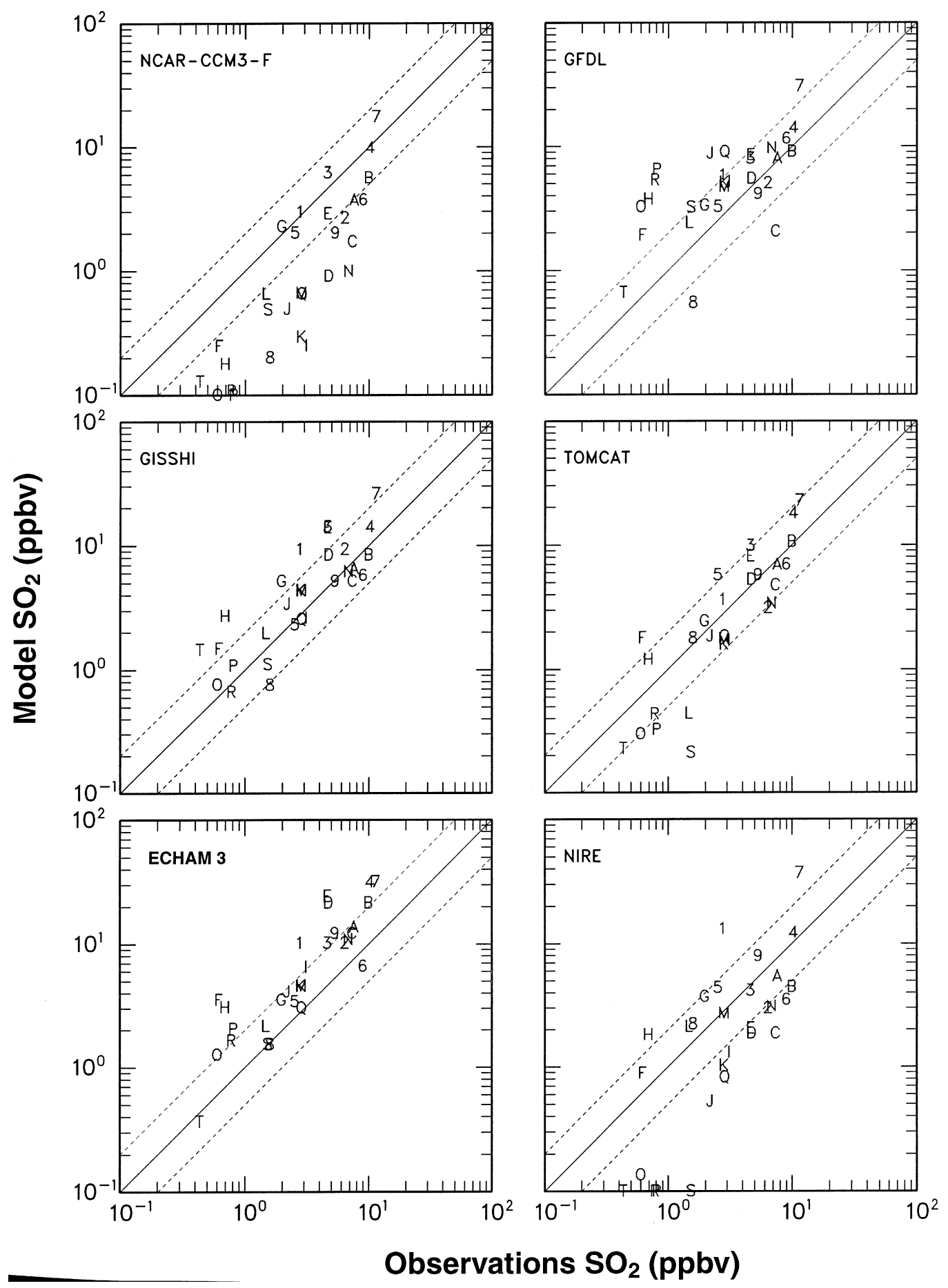


C

$\mathrm{SO}_{4}$ January US (EMEFS)

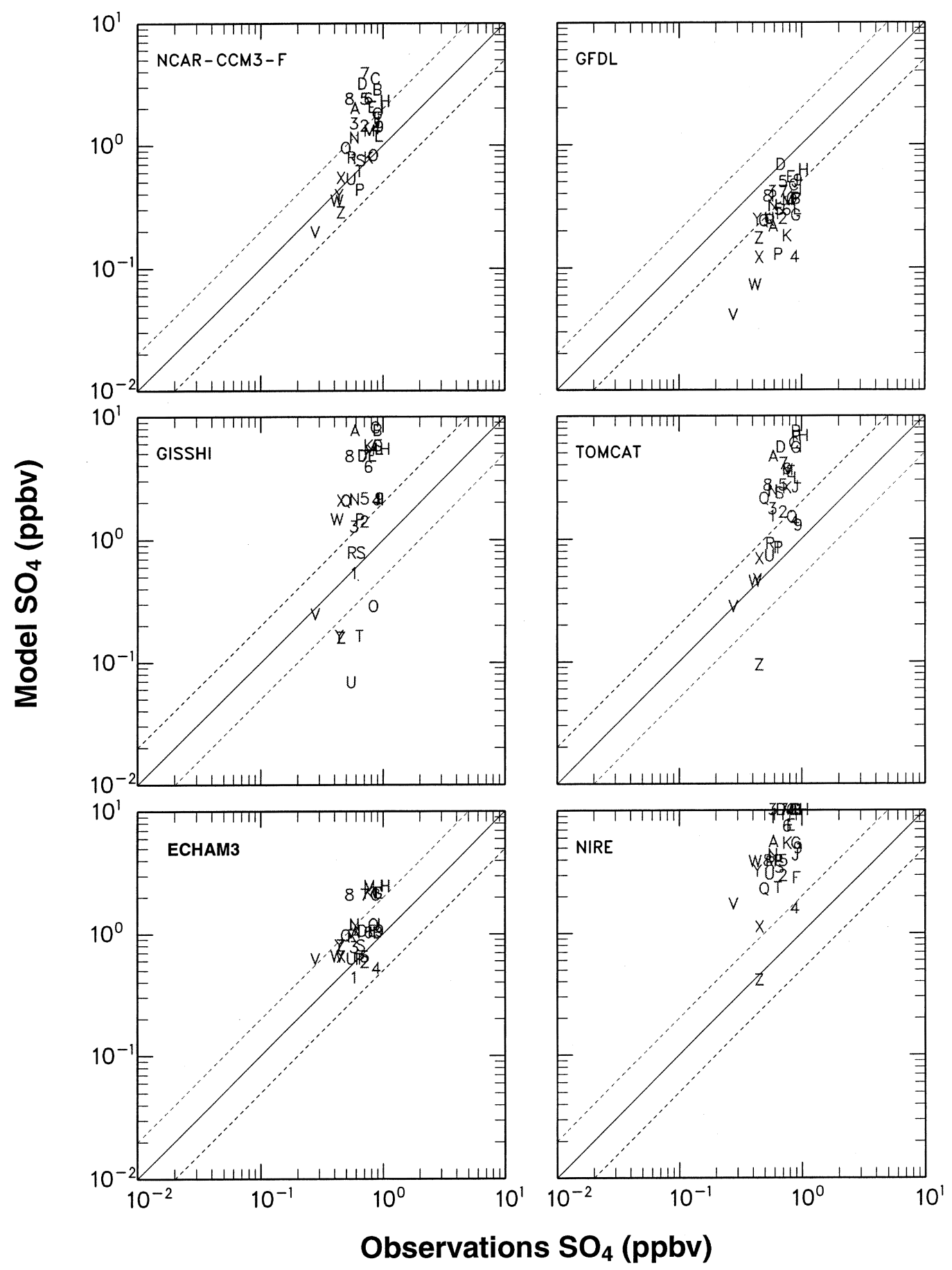




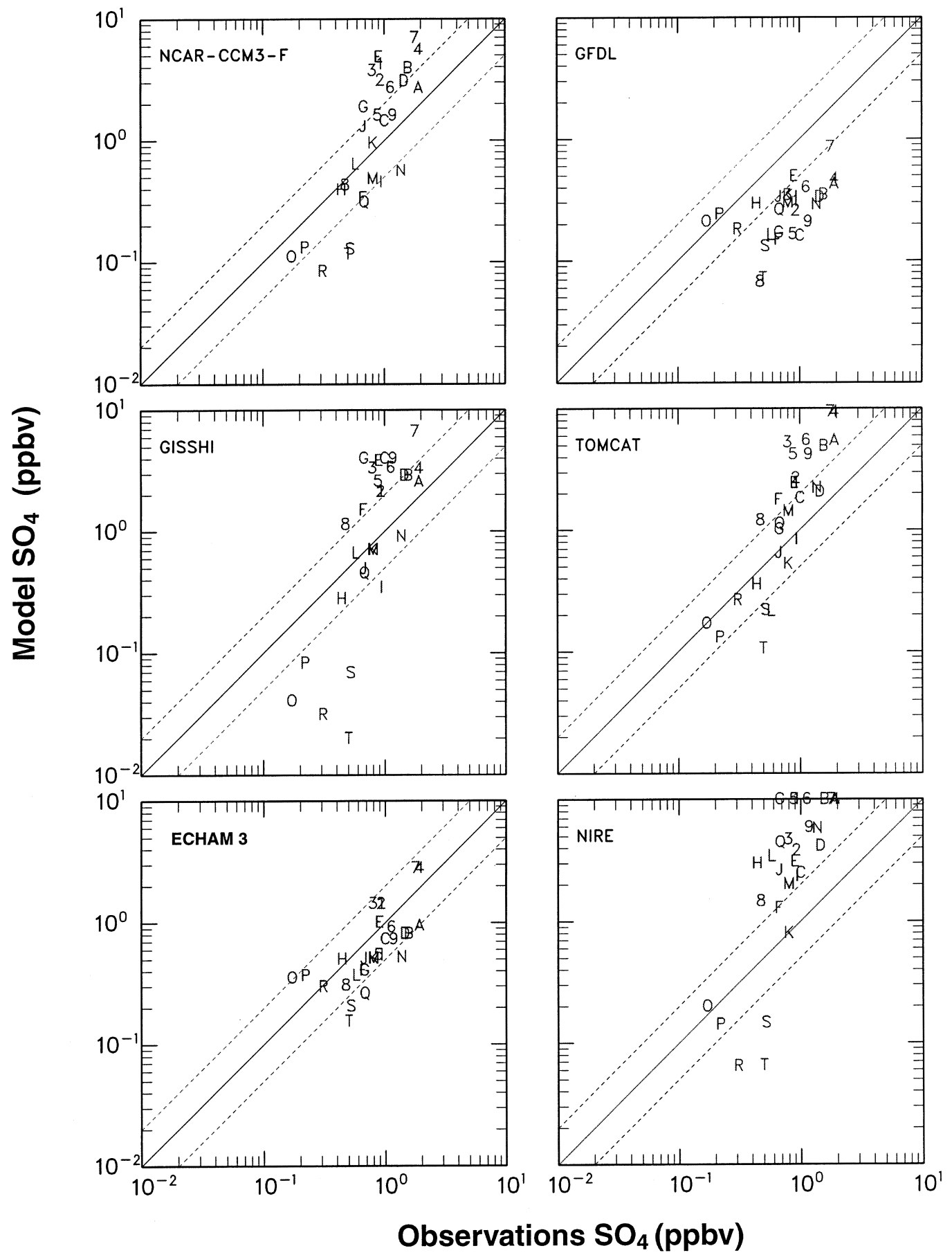

Tellus 52B (2000), 4 
that an agreement to within a factor of 2 of the measured mean $\mathrm{SO}_{2}$ value on a point by point basis constitute a good simulation (the dashed lines in the figures). No model was able to achieve this kind of agreement at all the measured points. The better models agreed with the observations to this degree at about $70 \%$ of the US/Canada points and about $50 \%$ of the European points. A striking characteristic of the $\mathrm{SO}_{4}^{2-}$ observations was the very small range of variation (a factor of $2-3$ between $\min$ and $\max$ ) in measured values over the North American (EMEFS) region, in contrast to the European region. All models showed a much larger variation over North America than the observations. The ECHAM model showed the best agreement in $\mathrm{SO}_{4}^{2-}$ over both regions, although its scores in the $\mathrm{SO}_{2}$ simulation were similar to the other models. While the predicted $\mathrm{SO}_{2}$ concentrations in January differ markedly between models, the agreement was often better in July (not shown), after excluding the outliers.

The much higher range of modelled concentrations in January sulfate concentrations than the observations may be related to a weak northward transport in all of the models in winter out of the source regions. We note that this mixing (as diaggnosed by the range of concentrations) was smaller in models with higher horizontal resolution than the lower resolution models. This difference in transport did not contribute to an improved simulation over the evaluation regions however.

4.2.2. Polar Regions. Radon/lead. As seen in the radon and lead measurements of Fig 6 and Table B1 of Rasch (1999), all models isolate the Antarctic coastal site (Dumont D'Urville) from southern mid-latitudes sources in summer (DJF), resulting in lower modelled means and variance than observed, particularly for lead. Observed concentrations show a maximum in austral summer with a rapid decrease in the spring. Only 2 models predict their lowest values in spring and none have the maximum in summer. Ten of 13 models simulate the maximum in austral winter and the minimum in summer. Since all models show an increase in lead concentrations with height, this underestimation could also be attributed to the poleward transport occurring at too high altitudes with little downward mixing by the models. Note that the South Pole is actually higher in elevation than the coast, which may help explain the higher observed concentrations at the South Pole (annual mean $48 \mu \mathrm{Bq} / \mathrm{SCM}$ ) than at the edge of Antarctica $(14-28 \mu \mathrm{Bq} / \mathrm{SCM})$. This feature is only captured by 2 models. This difference between model and observed behavior could be due to inaccurate transport by the winds in this region. Even models based on assimilated winds have difficulty near Antarctica, presumably because the sparse meteorological observational network allows analysed winds still largely in error there. It has also been suggested by Polian et al. (1986) that high summer concentrations in models could be explained by strong convective activity lifting up radon over the southern continents followed by advection southwards. The signature of an isolated southern hemisphere surface region is also seen in the lead simulation. All the models tend to underpredict the surface concentrations by $50 \%$ to $100 \%$ throughout the year, have the wrong seasonality and overestimate the deposition flux.

Because the modelled deposition fluxes of lead are much too high in Antarctica, we believe that the model deficiencies are due not only to an underestimation of the transport to polar regions but also to shortcomings in the treatment of deposition. The dry deposition velocity suggested for this experiment of $0.1-0.2 \mathrm{~cm} \mathrm{~s}^{-1}$ may be too high over cold ice surfaces by one order of magnitude (Ganzeveld, personal comminication). In particular, if the PBL is very stable this may result in a depletion of the surface layer lead. The zonal mean dry deposition flux between $30^{\circ} \mathrm{S}$ and the South Pole is much lower than the wet deposition flux in all model simulations. The wet deposition flux at $30^{\circ} \mathrm{S}$ is between 40 to $50 \mathrm{mBq} \mathrm{m}^{-2} \mathrm{yr}^{-1}$ and lower than $10 \mathrm{mBq} \mathrm{m}^{-2} \mathrm{yr}^{-1}$ at $60^{\circ} \mathrm{S}$ in all the models and all models show a decrease toward the pole without any discernable differences between models

Fig. 5. (A) The correlation between modeled and measured values for $\mathrm{SO}_{2}$ at gridpoints in North America during January. (B) The correlation between modeled and measured values for $\mathrm{SO}_{2}$ at gridpoints in Europe during January. (C) The correlation between modeled and measured values for $\mathrm{SO}_{4}^{2-}$ at gridpoints in North America during January. (D) The correlation between modeled and measured values for $\mathrm{SO}_{4}^{2-}$ at gridpoints in Europe during January. 

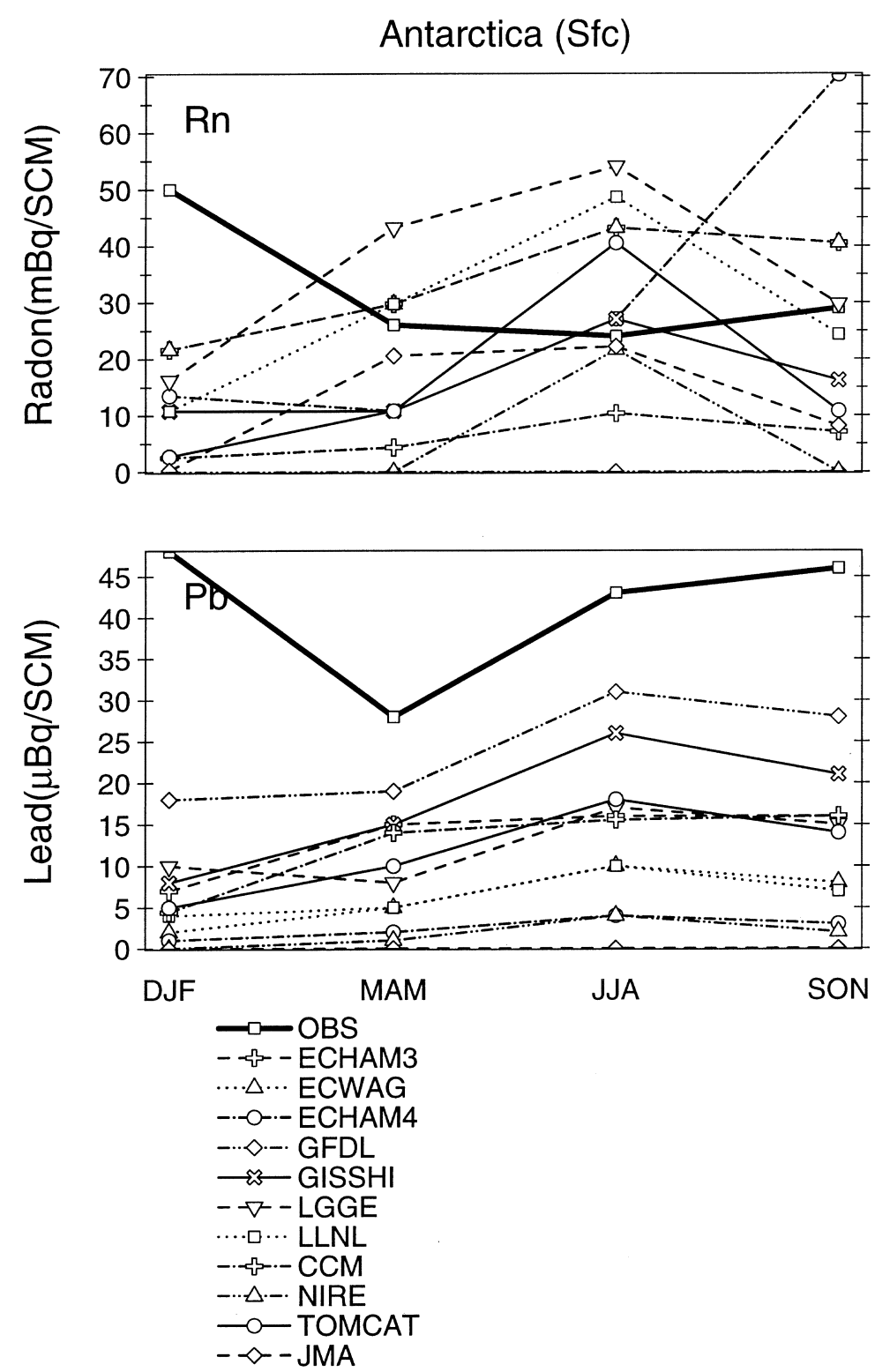

Fig. 6. Seasonal variations in radon and lead over Antarctica for the models (various thin line patterns) and the observational estimate (as the heavy black line).

with good or bad performance. Therefore, the excessive simulated deposition rates may arise from poleward transport in the upper troposphere, or be due to a too efficient wet scavenging at low temperatures. The corresponding underprediction of the surface concentrations could also be attrib- uted to a too weak downward transport over Antarctica at certain times of the year.

The situation is somewhat different in the Arctic where we compared the models to observations over Greenland. As at Antarctica, 12 of 13 models underestimate the annual mean surface concentra- 
tions (see Table 7), 10 models are in bad agreement with the observations, and all models overestimate the deposition, 12 of them seriously. In contrast to Antarctica only 3 show an incorrect seasonality and 5 even capture the seasonality qualitatively. In particular, the low summer concentrations are very well simulated by all the models. Only 2 models (GISSHIY and GFDL) do a reasonable job during the season of Arctic haze (winter and spring) when concentrations are as high as the annual mean values over the western US. Both models predict Arctic values between 250 and $500 \mu \mathrm{Bq} / \mathrm{SCM}$. As the GISSHIY model exhibits relatively low radon concentrations in the Arctic, the high lead values are due to a longer residence time or due to a low scavenging rate in midlatitudes during the Arctic haze season. The other models underpredict the concentrations during these seasons.

$S O_{x}$. Models also differed in their ability to capture the absolute magnitude and seasonal variation of $\mathrm{SO}_{x}$ in the Arctic. Only one model had concentrations near those observed (but it's concentrations in the source regions were too high). The seasonal variation in the Arctic was reasonable for 2 of the full sulfur models, but nonexistent in the third. The lower resolution models tended to transport the $\mathrm{SO}_{2}$ and $\mathrm{SO}_{4}^{2-}$ more easily to the Arctic, and this may explain in part their better simulation of elevated levels of sulfate, also seen in the observations. In comparing the predicted concentrations at Alert, only one was able to capture the high concentrations expected in January. The seasonal cycle was nearly absent in some models, while others produced a cycle close the observed factor of 10 difference between summer and winter. The largest differences in $\mathrm{SO}_{2}$ between the models lie in the near continental gradients. These differences tend to reflect the resolution at which the simulations were run, with the highest resolution models showing the strongest gradient and the lower resolution models the weakest. A similar pattern is seen in $\mathrm{SO}_{2}$ dry deposition rates, with the highest resolution model showing deposition confined to the source areas, and the lower resolution models showing higher deposition in remote areas.

4.2.3. Near continent stations. Radon. Radon is a good tracer for transport from a continental region to oceanic regions, since its sources are largely continental and its lifetime is short. At Bermuda, the models show about the right phase seasonal cycle, but mean values are often 2-4 times too high compared to the observations (Fig. 8). Most models predict higher concentrations than observed during winter. Examination of the modelled surface radon gradient from the east coast of the USA to $60^{\circ} \mathrm{W}$ shows no clear indication about whether models run at high horizontal and/or vertical resolution perform better at simulating radon at this near-continental site. However, ECHAM4 simulations at T30 compares more favourably with observations at Bermuda than ECHAM3 at the lower T21 resolution in the winter. In the summer, there is very little difference.

Lead. The lead simulation at 3 islands stations (Bermuda $\left(64^{\circ} \mathrm{W}, 32^{\circ} \mathrm{N}\right)$, Barbados $\left(59^{\circ} \mathrm{W}, 13^{\circ} \mathrm{N}\right)$ and Izania $\left(17^{\circ} \mathrm{W}, 28^{\circ} \mathrm{N}\right)$ were evaluated; those for Bermuda are shown in Fig 7. The bias between the modelled and observed concentration is largest at Bermuda and smallest at Izania. All models underpredict mean concentrations at each of these stations. The problem is worst in summer; at Bermuda the annual mean model concentrations show a wide range from $36 \mu \mathrm{Bq} / \mathrm{SCM}$ up to $678 \mu \mathrm{Bq} / \mathrm{SCM}$ with $380 \mu \mathrm{Bq} / \mathrm{SCM}$ being the observed value. Ten models underestimate the concentration and 3 overestimate it. Since the models overestimate radon at these stations, the underestimate of lead suggests excessive scavenging, during transport to the islands. The annual mean deposition at Bermuda was much better represented by the models.

4.2.4. Remote island stations. Radon. Transport of radon from continental regions to the remote ocean sites was also examined in the northern hemisphere by comparing with observations at Mauna Loa $(20 \mathrm{~N}, 150 \mathrm{~W}, 2.8 \mathrm{~km}$ or $\sim 600 \mathrm{hPa})$ (Harris, et al., 1992, Whittlestone, personal communication, 1995) and aircraft data collected at $\sim 200 \mathrm{hPa}$ (Kritz, 1990). The latter dataset was used in the 1993 WCRP workshop and, at that time, the majority of models fell below the observed median concentration (Jacobs et al., 1997). The same comparison here suggests the models have improved: model medians agree to within a factor of 2 with observations and the observed range of variability is also much better. Note that the observations were made at $200 \mathrm{hPa}$, 

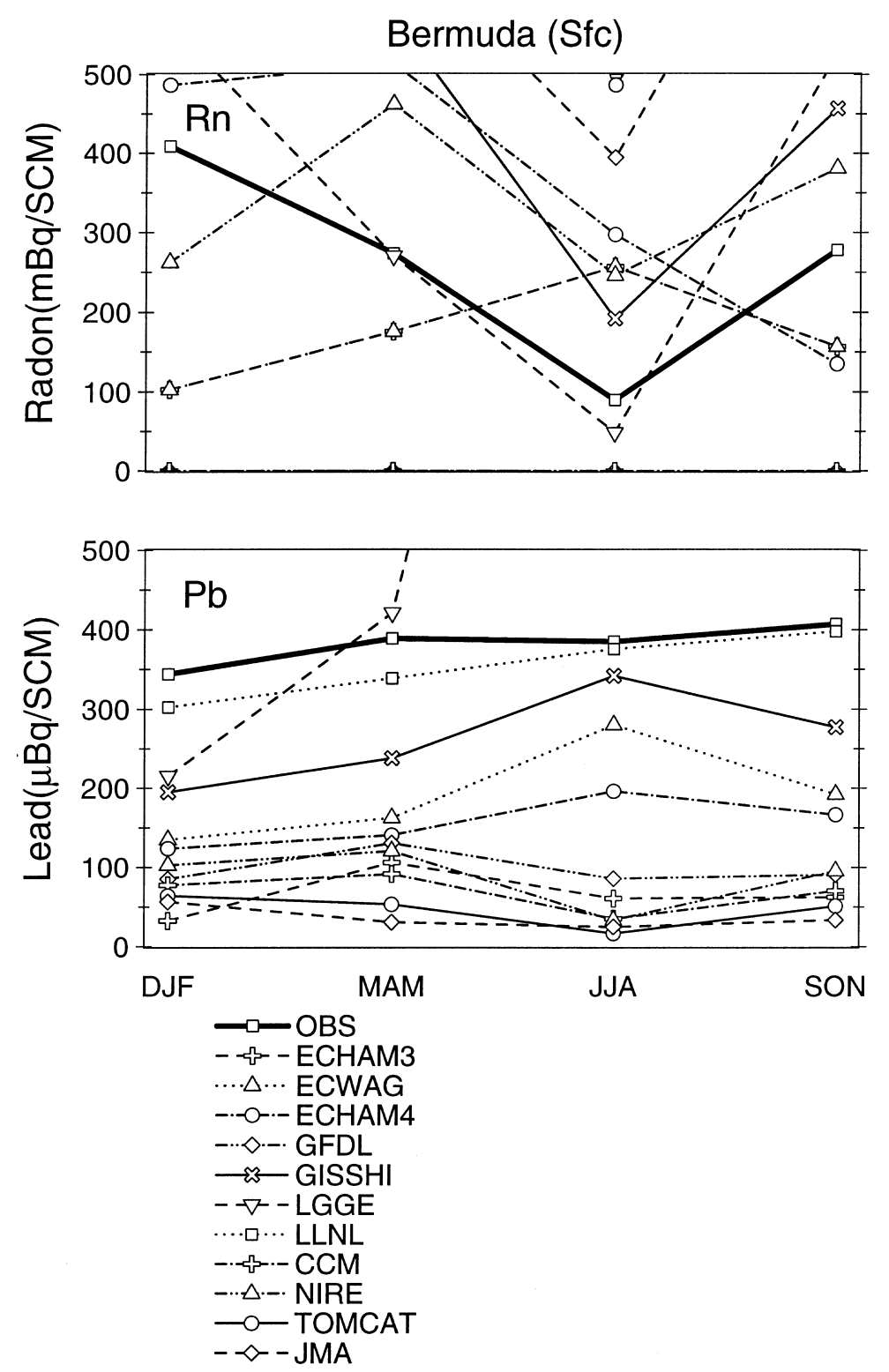

Fig. 7. Seasonal variations in radon and lead over Bermuda for the models (various thin line patterns) and the observational estimate (as the heavy black line).

while the model results were extracted at $300 \mathrm{hPa}$, which may indicate that the models now overpredict concentrations at $200 \mathrm{hPa}$. At $600 \mathrm{hPa}$, all models seriously underestimate observations by a factor of $4-5$ in the summer months (JJA) although the daily variability is well represented. At this site in DJF agreement is somewhat better although many models still underestimate the observations by a factor of 2 or more. The discrepancies in summer could arise from meteorological factors. For example, the UKMO model, which had relatively strong convection over Asia and a jet stream located further south than most models had a substantially better summer simulation than 
most other models. Kasibhatla, Mahowald and Whittlestone (personal communication) have suggested that the bias may be explained by an underestimate in radon emissions from Asia. However increasing the Asian emissions would also increase upper troposphere concentrations over the Southern California region and this would probably degrade the simulation there.

Radon simulations were also compared to observations for remote southern hemisphere sites at Crozet $\left(46^{\circ} \mathrm{S}, 51^{\circ} \mathrm{E}\right)$, Amsterdam Island $\left(40^{\circ} \mathrm{S}\right.$, $\left.80^{\circ} \mathrm{E}\right)$, Kerguelen Island $\left(50^{\circ} \mathrm{S}, 70^{\circ} \mathrm{E}\right)$, Cape Grim $\left(41^{\circ} \mathrm{S}, 142^{\circ} \mathrm{E}\right)$ and Dumont D'Urville $\left(67^{\circ} \mathrm{S}, 140^{\circ} \mathrm{E}\right)$ (Lambert, 1970; Polian et al., 1986; Heimann et al., 1990; Ramonet, et al., 1996). As noted in Jacob et al. (1997), the observations in the Indian Ocean exhibit a winter (JJA) maximum due to greater storm activity carrying radon away from the African continent. The models have the same pattern, but show more variability and in many cases higher medians than the observations, particularly at Crozet during JJA. This is probably due to errors in the statistics of winter storms or PBL mixing. This is particularly true of LLNL, LMD and GFDL whose upper quartile range exceeds $243 \mathrm{mBq} / \mathrm{SCM}$ (compared to observed value of $108 \mathrm{mBq} / \mathrm{SCM}$ ). At other sites in the Indian Ocean, agreement is within a factor of 2-3 with models capturing well the reduced variability in the radon concentrations in the summer (DJF) months. Whilst most models perform well at Cape Grim, they do not capture the high observed radon concentrations in May and June. The models tended to overpredict concentrations slightly at Crozet, but there was no general trend at Kerguelen and Amsterdam Island, where the models both overpredicted and underpredicted the annual mean concentration.

Lead. Four remote islands (Amsterdam Island (77E, 37S), Kerguelen (69E, 49S), Isla de Pascua $(109 \mathrm{~W}, 27 \mathrm{~S})$ and American Samoa $(171 \mathrm{~W}, 14 \mathrm{~S})$ in the central Pacific and Indian Ocean showed an average concentration of $32 \mu \mathrm{Bq} / \mathrm{SCM}$. An interesting feature is that observed concentrations over the Indian Ocean are a factor of 3 lower than those over the central Pacific. The Indian sites are located at higher latitudes than the pacific sites (further from the source regions), and this may explain the difference in mean concentration. The feature is only captured by $1 / 3$ of the models. At the Indian Ocean sites we found the largest over- predictions. However, 7 models underestimate the observations even there. At Isla de Pascua and American Samoa, where the highest concentrations are observed in austral winter, $2 / 3$ of the models underestimate the concentrations. The scatter between the models is largest at American Samoa, the most remote of the measurement sites. Only 2 models show a reasonable agreement there, all the others overestimated the concentrations.

At Fanning Island (159W, 3.5N), Oahu (158W, $21.5 \mathrm{~N})$, Midway Islands (177W, 28N) and Milford Haven $(5 \mathrm{~W}, 51 \mathrm{~N})$ only annual deposition fluxes (54.5, 45.5, 36.2 and $85 \mathrm{~Bq} \mathrm{~m}^{-2} \mathrm{yr}^{-1}$, respectively) were reported. The agreement between these observations and the models was best at Milford Haven, where 11 models were within $\pm 50 \%$. This level of agreement was seen in 8 models at Oahu by 6 models at Midway Islands and by 5 models in the Fanning Islands. Wet deposition fluxes at islands are known to be influenced by the island precipitation effect, and this may explain part of the discrepancy in deposition rates here.

Generally, the comparison with observations at islands show a clear distinction between models which predict too low concentrations at nearly all sites ( 8 models) and such which tend to overpredict it (5 models). This systematic difference between models cannot be seen at continental or polar sites, but appears to be consistent with the calculated global lifetime of lead shown in Table B1 (Rasch, 1999), and indicates a systematic over, or underprediction of the scavenging rates. This clustering could not be characterized in terms of model resolution, or level of sophistication of the physical parameterizations, or on- versus offline models, because models with similar attributes fell into both clusters (e.g., the MATCH and CCM models shared the same scavenging parameterization but fell into separate clusters). The clustering is most likely to be controlled by the precipitation distribution itself. This emphasizes that observations at remote sites are useful to estimate the global burden and the residence time of chemical constituents.

\subsection{Vertical profiles}

Although the number of free tropospheric lead, $\mathrm{SO}_{2}$ and $\mathrm{SO}_{4}^{2-}$ have been increasing rapidly in the last few years, there are still only a relative few composites of the species. This lack of data 

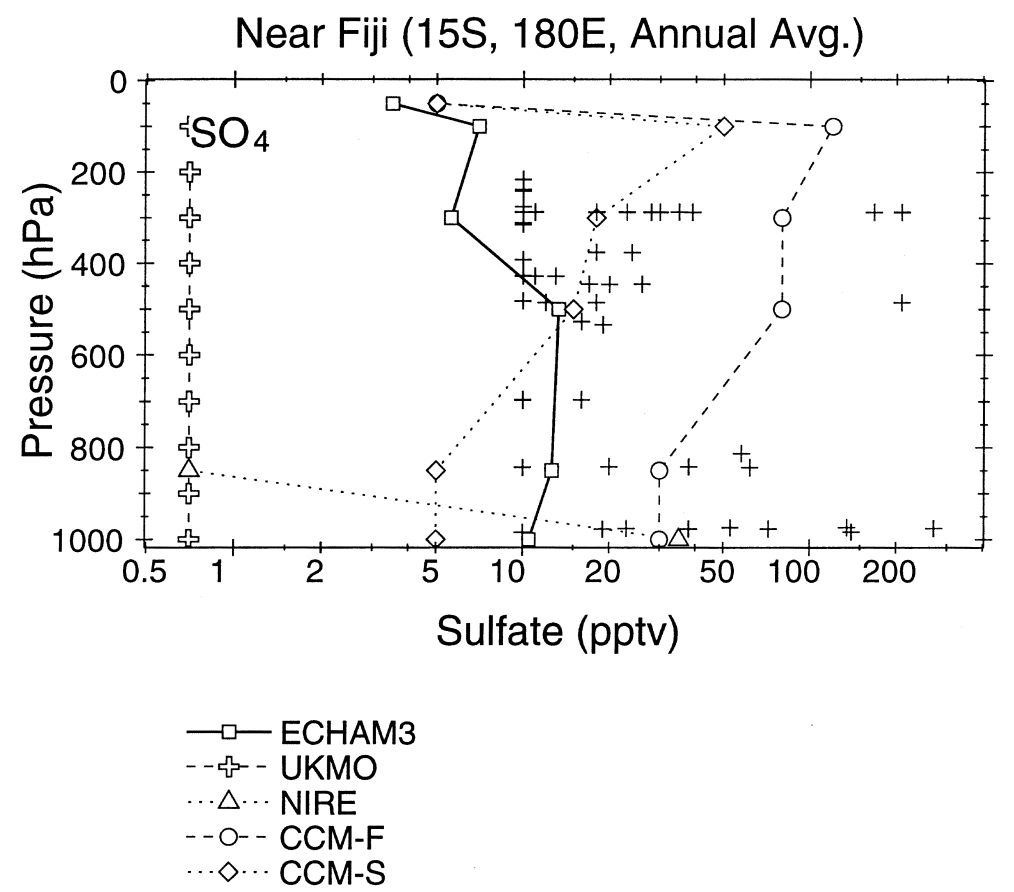

Fig. 8. Model predicted annual averages of sulfate in the Fiji region compared to measured values during September and October from the recent PEM tropics measurement campaign (Thornton et al., 1999). Note that measured values below the detection limit of 10 pptv were not plotted.

make it very difficult to assess the realism of model simulation in the mid and upper troposphere. Only a few modellers reported lead profiles, and the observations were too sparse for much confidence. We did attempt to compare model results with these measurement during the workshop, but will not report on them here because the uncertainty in observational estimates is so large. The situation is not much different for radon and sulfur species. Most of the observational radon profiles available to us were also used in Jacob et al. (1997). The model radon profiles over the Central US were generally within a factor of 2 of these observations and differences with the previous report are small. The models results show more scatter about the observations in the lower troposphere where boundary layer processes play an important role, than seen in middle and upper troposphere. Comparison with recent measurements near San Francisco, USA showed similar agreement aloft although almost all models substantially overpredict the surface concentrations. It appears that the average measurements are more representative of clean marine conditions (with on-shore winds) whereas the models include some impact from areas more representative of a continental site (since San Francisco is treated as a single land box with significant surface emissions). Better agreement is found when comparing individual profiles with models using analysed winds for that period (Stockwell, personal communication).

To provide an idea of the variability of the models and observations over a remote region we show profiles of $\mathrm{SO}_{4}^{2-}$ in Fig. 8 for a subset of the participating models in the vicinity of Fiji (15S, 180E), and some observations from the recent PEM Tropics field program (Talbot et al., 1998). The PEM measurements were taken from 3 flights during september and october of 1996. At many levels the measured values differ by an order of magnitude over the 3 days the sampling was made. The model profiles were not explicitly requested for the comparison but were extracted (by hand) from contour plots of latitude/height cross-sections on the dateline. They represent rough averages on the dateline between the equator and 30S. The 
averages were constructed from contours spaced approximately every 1,2 , and $5 \times 10^{\mathrm{n}}$ pptv. Thus the profiles drawn are quite rough, but illustrate the very large differences between models, and the very large scatter in the measurements. The profiles highlight the difficulty in such a model/measurement intercomparison. Since most models did not include the DMS source for sulfate, a quantitative comparison should not be attempted.

\section{Summary and conclusions}

As indicated in the introduction, it was the intent of this paper to survey the spectrum of model representation of deposition processes, and their simulations for a few species. We wished to highlight areas where models agree or disagree with each other, and the observations in terms of their ability to simulate the distribution and deposition of soluble species arising from well defined sources. The differences arise because of variations between models in the representation of transport and deposition processes. We summarize briefly some of the conclusions from the intercomparison in these last paragraphs.

The radon comparison was particularly useful in highlighting transport problems. Most models were able to simulate the appropriate seasonal cycle over continental and near continental sites although they often overestimate the near surface mixing ratio. This may be due in part to differences in sampling strategy between models and observations, but there were clear differences associated with boundary layer transport and convective processes between models that must also play a part. The analysis suggests that spatially varying emissions may also be important in explaining the systematic discrepancies between most of the models (which used uniform emissions over land) and observations. Discrepancies between model and observations were much larger in regions remote from the source. Radon observations show higher wintertime than summertime concentrations at island sites in the Indian Ocean. Models show the same seasonality as the observations, but exaggerate the seasonal effect of the Austral winter storms by carrying too much radon to these remote regions. All models isolated the Antarctic coastal site from Australian sources in summer; this is opposite to the observations, which show larger means and variances during summer (as contrasted with the Indian Ocean sites). All the models showed excessively large variances in winter at remote southern hemisphere surface sites, possibly to the statistics of winter storms, or the vertical exchange between the marine boundary layer and the free troposphere. Simulations over Mauna Loa (about $600 \mathrm{hPa}$ ) seriously underestimated observational values. These discrepancies come from incorrect meteorological transport, or from an underestimate in the strength of radon emissions over Asia.

Comparisons against lead measurements add deposition processes as factors contributing to model error. Monthly averaged model results were compared against lead observations for 11 regions in terms of surface mixing-ratios and deposition fluxes. Simulated concentrations and deposition fluxes of lead agreed with observations to better than a factor of 2, with most models having biases of less than 0.5 in all regions. All the models are able to simulate the annual mean mixing-ratios of lead over Europe, US, India and South-America to about $40 \%$ relative accuracy (a relative bias of about 0.2). In Europe, the observations show a west (high lead) to east (low lead) gradient not found in any model. The reason for the observed gradient is not clear but may again be due to a varying regional radon source strength present in reality and absent in the models. Over the US all the models fail to simulate the annual cycle of surface lead concentrations. They underestimate wintertime concentrations, when observed concentrations are highest, and overestimate slightly summer surface concentrations. As the radon model results show the same behavior, the reason for this may be shortcomings in the vertical exchange of both radon and lead during continental wintertime. We also found substantial overestimates over Europe and an underestimate over Japan in the deposition fluxes. The Japan deposition flux measurements were the highest reported globally and are associated with the outflow from Asia during the winter monsoon.

Remote site concentrations of lead are controlled by long-range transport (and indirectly by scavenging and convective transports as well) and, like radon, were much more difficult to model than concentrations near the source regions. The scatter of modelled surface concentrations over remote islands in the tropics (Barbados and 
American Samoa) was as large as the measured concentrations themselves. Models seriously underestimated surface mixing-ratios over the Antarctica and Greenland. The underestimate was accompanied by an overestimate of deposition fluxes. North-South cross-section of lead and radon at the date-line and at $27^{\circ} \mathrm{E}$ were compared between models. Radon cross-sections agreed much more closely between models than the corresponding lead concentrations; therefore, differences between the model results reflect mainly the different treatment of the scavenging processes or differences in the hydrological parameters used to parameterize the scavenging.

Similar discrepancies in remote regions were also evident in the $\mathrm{SO}_{x}$ simulations. Model differences were large, especially with respect to their vertical distribution of both concentrations and removal rates. The difference between concentrations of $\mathrm{SO}_{2}$ between models using the full chemistry and simple chemistry representations indicate the importance of a reasonable characterization of the processes controlling its oxidation. Differences associated with transports of $\mathrm{SO}_{2}$ were overwhelmed by prescription of a simple first order transformation rate from $\mathrm{SO}_{2}$ to $\mathrm{SO}_{4}^{2-}$ in the free troposphere. Even among the more sophisticated models, the distribution of $\mathrm{SO}_{4}^{2-}$ and lead mixing ratios routinely vary by a factor of $2-5$ in the free troposphere, with similar differences in global burden and residence time. The model differences are largest in the upper troposphere. These differences are due both to transport (primarily the rapid transport associated with convec-

Table 6. A description of the participating models resolved scale resolution and transport methods

\begin{tabular}{|c|c|c|c|c|c|c|}
\hline Name & Institute & $\begin{array}{l}\text { Horizontal } \\
\text { resolution } \\
\text { (degrees) }\end{array}$ & $\begin{array}{l}\text { Vertical } \\
\text { resolution } \\
\text { \#levs/ } \\
\text { model top } \\
(\mathrm{km})\end{array}$ & $\begin{array}{l}\text { Timestep } \\
\text { or } \\
\text { archive } \\
\text { interval }\end{array}$ & $\begin{array}{c}\text { Transport } \\
\text { method }\end{array}$ & Comments/definitive references \\
\hline CCM- $\Omega$ & NCAR & $2.8 \times 2.8$ & $18 / 35$ & 20 & $\operatorname{SLT}(\mathrm{I})$ & $\begin{array}{l}\text { intermediate model between CCM2 } \\
\text { (Hack et al., 1994) and CCM3 } \\
\text { (Kiehl et al., 1996) }\end{array}$ \\
\hline ECHAM3 & MPI Hamburg & $5.6 \times 5.6$ & $19 / 25$ & $45 \mathrm{~min}$ & $\operatorname{SLT}(\mathrm{I})$ & Roeckner et al. (1992) \\
\hline ECHAM4 & MPI Hamburg & $3.7 \times 3.7$ & $19 / 25$ & $30 \mathrm{~min}$ & $\operatorname{SLT}(\mathrm{I})$ & Roeckner et al. (1996) \\
\hline ECWAG & Univ. Wag & $5.6 \times 5.6$ & $19 / 25$ & $45 \mathrm{~min}$ & $\operatorname{SLT}(\mathrm{I})$ & $\begin{array}{l}\text { identical meteorology to above ECHAM3, } \\
\text { but chemistry and scavenging differ }\end{array}$ \\
\hline GFDL & GFDL & $2.5 \times 2.5$ & 11 & $6 \mathrm{~h}$ & $\mathrm{FD}(\mathrm{O})$ & $\begin{array}{l}\text { meteorology from GCM (Kasibhatla } \\
\text { et al., 1997) }\end{array}$ \\
\hline GISSHIY & GISS/Har/Yale & $4 \times 5$ & 9 & $6 \mathrm{~h}$ & $\operatorname{SOM}(\mathrm{O})$ & $\begin{array}{l}\text { Balkanski et al. (1993); Koch et al. } \\
\text { (1996) }\end{array}$ \\
\hline GRANTOUR & LLNL & $4 \times 4$ & 10 & $24 \mathrm{~h}$ & $\operatorname{Lag}(\mathrm{O})$ & Chuang and Penner (1995) \\
\hline LMD/LGGE & LMD/LGGE & $5.6 \times 3.6$ & 11 & $6 \mathrm{~h}$ & $\operatorname{SOM}(\mathrm{I})$ & $\begin{array}{l}\text { Genthon and Armengaud (1995); } \\
\text { Preiss and Genthon (1997) }\end{array}$ \\
\hline MATCH-EC & NCAR & $2.8 \times 2.8$ & 19 & $6 \mathrm{~h}$ & $\operatorname{SLT}(\mathrm{O})$ & $\begin{array}{l}\text { meteorology from ECMWF analysis } \\
\text { (Mahowald et al., 1997) }\end{array}$ \\
\hline MATCH-NMC & NCAR & $2.8 \times 2.8$ & 19 & $6 \mathrm{~h}$ & $\operatorname{SLT}(\mathrm{O})$ & $\begin{array}{l}\text { meteorology from NCEP analysis } \\
\text { (Mahowald et al., 1997) }\end{array}$ \\
\hline MUTM & $\mathrm{CRC}$ & $5.6 \times 5.6$ & 9 & $24 \mathrm{~h}$ & $\mathrm{SP}(\mathrm{O})$ & Law et al. (1992) \\
\hline NIRE & NIRE & $2.5 \times 2.5$ & 15 & $12 \mathrm{~h}$ & $\operatorname{SLT}(\mathrm{O})$ & $\begin{array}{l}\text { Taguchi (1996); Meteorology from } \\
\text { ECMWF analysis }\end{array}$ \\
\hline STOCHEM & UKMO & $10 \times 10$ & 10 & - & $\operatorname{Lag}(\mathrm{O})$ & stevenson.ea:radon \\
\hline TOMCAT & Camb. Univ. & $2.8 \times 2.8$ & 19 & $30 \mathrm{~h}$ & $\operatorname{SOM}(\mathrm{O})$ & $\begin{array}{l}\text { Chipperfield et al. (1993); Meteorology } \\
\text { from ECMWF analysis }\end{array}$ \\
\hline TRA95 & JMA & $2.8 \times 2.8$ & 21 & $12 \mathrm{~h}$ & $\operatorname{Lag}(\mathrm{I})$ & Taguchi (1996) \\
\hline UKMO-UM & UKMO & $2.5 \times 3.75$ & 19 & $30 \mathrm{~min}$ & $\operatorname{Eul}(\mathrm{I})$ & Cullen (1993) \\
\hline
\end{tabular}

See text for a discussion of the terms in the table. SOM, SLT, and SP stand for "Second order moments", "semiLagrangian" and "spectral" transport methods respectively. The (I) or (O) in the transport method table entry indicates whether the model is run as an "inline" or an "offline" model. 
tion) and to the prescription of the removal processes during their transit to the upper troposphere and their removal there. None of these aspects is well characterized by observations. This points to the need for a long-term strategy of measurement of tracers that are able to discriminate between the processes of vertical redistribution and scavenging.

It is clear that our ability to understand the processes of scavenging and deposition of soluble trace species and those processes subsequent control on the vertical and horizontal distribution of species are severely limited by the lack of observations of relevant tracers in the free troposphere. Jacob et al. (1997), in their evaluation of the state of the art of global modelling of convection and boundary layer processes, concluded that "... results show that most established 3dimensional synoptic models simulate boundary layer mixing and deep convection in the troposphere to within the constraints offered by observed seasonal averages of radon concentrations at different altitudes". While this is probably true for the scavenging and deposition processes as well, our ability to characterize these processes from observations in remote parts of the globe (either the free troposphere or remote surface sites) is poor. Models differ substantially in their simulations of soluble species and observations (particularly at altitude) do not yet provide us with strong seasonal constraints on the reality of the simulations. We believe that attempting to compare model simulations on an event by event basis, using off-line chemical transport models, or "nudged" general circulation models with meteorological fields that are strongly constrained by observations will assist in such a comparison, because these soluble species vary on such small time and space scales that it is difficult to establish their definitive long-term climatology. Long-term climatologies do help in defining "average" properties of the model and atmospheric properties and thus are important in understanding the fundamental controlling processes in the atmosphere.

The processes entering into the control of shortlived trace species in the atmosphere are so complex that more effort needs to be made to isolate component processes, both in modelling and from an observational point of view. One possible solution would be the use of column models in which the driving meteorological processes are prescribed to be the same for all modelling groups, and only the relevant parameterizations are tested. So, for example, initial, and boundary conditions,

Table 7. A description of the participating models moist and dry deposition, and subgrid transport processes

\begin{tabular}{|c|c|c|c|c|}
\hline Name & $\begin{array}{l}\text { Moist convective } \\
\text { transport }\end{array}$ & $\begin{array}{l}\text { Dry turbulent } \\
\text { transport }\end{array}$ & $\begin{array}{l}\text { Cloud water } \\
\text { for chemistry and } \\
\text { wet deposition }\end{array}$ & $\begin{array}{c}\text { Dry } \\
\text { deposition }\end{array}$ \\
\hline CCM- $\Omega$ & penetrative & $\mathrm{Ri}+\mathrm{NL}$ & bulk & resistance \\
\hline ECHAM3 & penetrative & $\mathrm{Ri}$ & bulk & prescribed \\
\hline ECHAM4 & penetrative & $\mathrm{Ri}+\mathrm{TKE}$ & bulk & prescribed \\
\hline ECWAG & penetrative & $\mathrm{Ri}$ & bulk & prescribed \\
\hline GFDL & diffusive & diffusive & inferred & resistance \\
\hline GISSHIY & penetrative & $\mathrm{Ri}$ & none & none \\
\hline GISS2P & penetrative & $\mathrm{Ri}$ & none & none \\
\hline GRANTOUR & penetrative & $\mathrm{Ri}$ & $\mathrm{N} / \mathrm{A}$ & prescribed \\
\hline LMD/LGGE & penetrative & $\mathrm{Ri}$ & bulk & resistance \\
\hline MATCH-EC & penetrative & $\mathrm{Ri}+\mathrm{NL}$ & $\mathrm{N} / \mathrm{A}$ & prescribed \\
\hline MATCH-NMC & penetrative & $\mathrm{Ri}+\mathrm{NL} 8$ & $\mathrm{~N} / \mathrm{A}$ & prescribed \\
\hline MUTM & relax to mean & prescribed & $\mathrm{N} / \mathrm{A}$ & $\mathrm{N} / \mathrm{A}$ \\
\hline NIRE & none & $\mathrm{Ri}+\mathrm{NL}$ & inferred & prescribed \\
\hline STOCHEM & none & prescribed & N/A & $\mathrm{N} / \mathrm{A}$ \\
\hline TOMCAT & penetrative & $\mathrm{Ri}$ & $\mathrm{N} / \mathrm{A}$ & prescribed \\
\hline TRA95 & penetrative & $\mathrm{Ri}+\mathrm{TKE}$ & none & resistance \\
\hline UKMO-UM & penetrative & $\mathrm{Ri}$ & $\mathrm{N} / \mathrm{A}$ & resistance \\
\hline
\end{tabular}

See text for a discussion of the terms in this table. N/A indicates a description was not available or the process was not used. 
as well as tendencies by large-scale processes for temperature, moisture, and trace species distributions could be prescribed for a scavenging experiment. Then the evolution of the cloud water, precipitation and trace species distributions calculated by column model versions of the global model scavenging, microphysics and chemistry schemes can be directly compared in a fashion that excludes many of the factors complicating a careful evaluation in a fully 3 -dimensional context. We also recommend comparing models to observations of smaller temporal scale (daily mean and diurnal variation) since long-term averages are difficult to assess for species with high temporal variability.

\section{Acknowledgements}

We would like to thank the World Climate Research Programme and V. Savtchenko for funding the workshop. We thank Richard Larsen, G. Polian, and members of the EMEFS and EMEP science teams for providing their data to us prior to its publication. We thank Daniel Jacob and Brian Eaton for comments on the first draft of the manuscript and Henning Rodhe and an anonymous referee for their comments during the review process. Work at the UK Met Office was supported by the UK Department of Environment, Transport and the Regions under contract PECD/7/12/37.

\section{Appendix}

Table 6 provides a brief description of resolution and transport properties of the models participating in the intercomparison. The descriptions are intended to be descriptive in nature. More detail on each model is available in the cited references of the comments column. Table 7 indicates the type of hydrologic properties and deposition processes used by each model. We will briefly try to describe some of the terms used in the table, and put them into context within this study.

SOM, SLT, and SP stand for "Second order moments" (Prather, 1986), "semi-Lagrangian" (Rasch and Williamson, 1990) and "spectral" (Machenhauer, 1979) transport methods, respectively. These methods are all popular numerical techniques for moving constituents at the length scales resolved by each model's grid. The (I) or (O) in the transport method table entry indicates whether the model is run as in "inline" simulation (the meteorology is predicted and updated very frequently), or as an "offline" model (where meteorology is derived from archived values). We use the word penetrative to refer to a sub-gridscale moist convective transport parameterization like those advocated by Tiedtke (1989), where a parcel of air carries tracer and precipitation to its level of neutral buoyancy, entraining and detraining air as it rises. We use the term diffusive convection to refer to a scheme like that of Hack (1994) or Manabe et al. (1965) that refers to a local release of a convective instability. These schemes mix mass fractions of tracer locally between 2 levels before moving upward and repeating the process (if necessary). Dry turbulent processes are referred to as a "Ri" or Richardson number dependent scheme where turbulent mixing is parameterized as a local Fickian diffusion that depends upon the local stability of the column and the gradient of the tracer. "Non-Local" (NL) schemes (Holtslag and Boville, 1993) parameterize boundary layer transport by prescribing the column properties (the diffusion coefficients) of these turbulent processes in terms of surface fluxes of heat and moisture, and boundary layer depth. TKE parameterizations use a higher order closure method to estimate the turbulent properties of the boundary layer (e.g., ECHAM4). Cloud and moist deposition processes are identified as bulk processes when there are explicit predictive equations used for the formation of condensate, and its conversion to precipitating (Rasch and Kristjánsson, 1998). Given these quantities and a cloud volume, one can formulate explicit equations for the aqueous chemistry and scavenging required for oxidation of $\mathrm{SO}_{2}$ and/or removal of aerosol. We identify these processes as inferred when they use other quantities (e.g., the surface flux of precipitation and/or the column water vapor distribution) to construct surrogates for these processes (Kasibhatla et al., 1997). Dry deposition processes follow either a simple prescribed deposition velocity or use a resistance in series approach (Wesely, 1989). Please refer to the definitive reference cited in Table 6 for a complete description of these processes. 


\section{REFERENCES}

Balkanski, Y., Jacob, D., Arimoto, R. and Kritz, M. 1992. Distribution of ${ }^{222} \mathrm{Rn}$ over the North Pacific: implications for continental influences. J. Atmos. Chem. 14, 353-374.

Balkanski, Y., Jacob, D., Gardner, G. M., Graustein, W. M. and Turekian, K. K. 1993. Transport and residence times of continental aerosols inferred from a global 3-dimensional simulation of ${ }^{210} \mathrm{~Pb}$. J. Geophys. Res. 98, 20,573-20,586.

Benkovitz, C., Scholtz, M., Pacyna, J., Tarrason, L., Dignon, J., Voldner, E., Spiro, P., Logan, J. and Graedel, T. 1996. 1995 global gridded inventories of anthropogenic emissions of sulfur and nitrogen. J. Geophys. Res. 101, 29,239-29,254.

Boville, B. A., Jacob, D. and Prather, M. 1997. Global tracer transport models. Proceedings of a WCRP work shop on the parameterization of subgrid-scale trace transport. WMO/TD-no. 823 26, World Meteorological Organization, Geneva, Switzerland.

Chipperfield, M. P., Cariolle, D., Simon, P., Ramaroson, R. and Lary, D. J. 1993. A three-dimensiona modeling study of trace species in the arctic lower stratosphere during winter 1989-1990. J. Geophys. Res. 98, 7199-7218.

Chuang, C. and Penner, J. E. 1995. Effects of anthropogenic sulfate on cloud drop nucleation and optical properties. Tellus 47B, 566-577.

Cullen, M. J. P. 1993. The unified forecast/climate model Meteorol. Mag. 122, 81-94.

Feichter, J., Brost, R. and Heimann, M. 1991. Threedimensional modeling of the concentration and deposition of $210 \mathrm{~Pb}$ aerosols. J. Geophys. Res. 96, $22,447-22,469$

Feichter, J., Lohmann, U. and Schult, I. 1997. The atmospheric sulfur cycle and its impact on the shortwave radiation. Clim. Dyn. 13, 235-256.

Genthon, C. 1994. Antartic climate modeling with general circulation models of the atmosphere. J. Geophys Res. 99, 12,953-12,961.

Genthon, C. and Armengaud, A. 1995 Radon 222 as a comparative tracer of transport and mixing in two general circulation models of the atmosphere. J. Geophys. Res. 100, 2849-2866.

Giorgi, F. and Chameides, W. L. 1986. Rainout lifetimes of highly soluble aerosols and gases as inferred from simulations with a general circulation model. J. Geophys. Res. 91, 14,367-14,376.

Hack, J. J. 1994. Parameterization of moist convection in the NCAR Community Climate Model, CCM2. J. Geophys. Res. 99(D3), 5551-5568.

Hack, J. J., Boville, B. A., Kiehl, J. T., Rasch, P. J. and Williamson, D. L. 1994. Climate statistics from the NCAR community climate model CCM2. J. Geophys. Res. 99, 20,785-20,813.

Heimann, M., Monfray, P. and Polian, G. 1990
Modeling the transport of ${ }^{222} \mathrm{Rn}$ to subantarctic and antarctic areas. Tellus 42B, 83-99.

Holtslag, A. A. M. and Boville, B. A. 1993. Local versus nonlocal boundary-layer diffusion in a global climate model. J. Clim. 6, 1825-1842.

Jacob, D. J., Prather, M. J., Boville, B. A., Rasch, P. J., Feichter, J., Kasibhatla, P. S., Verver, G., Penner, J. E., Bergmann, D., Genthon, C., Balkanski, Y. J., Zimmermann, P., Beagley, S. R., Blackshear, W. T., Rotman, D. A., Chiba, M., Chipperfield, M., Brown, P. D., Shia, R.-L., Law, K., Reeves, C. and Brown, M. 1997. Intercomparison of convective and synoptic transport in global models using ${ }^{222} \mathrm{Rn}$ and other tracers. J. Geophys. Res. 102, 5953-5970.

Kasibhatla, P. Chameides, W. L. and St. John, J. 1997. A three-dimensional global model investigation of seasonal variations in the atmospheric burden of anthropogenic sulfate aerosols. J. Geophys. Res. 102, 3737-3760.

Kiehl, J. T., Hack, J., Bonan, G. B., Boville, B. A., Briegleb, B. P., Williamson, D. L. and Rasch, P. J. 1996. Description of the NCAR Community Climate Model (CCM3). NCAR Tech. Note, NCAR/TN-420+STR. Nat. Cent. for Atmos. Res., Boulder, Colo., USA.

Koch, D. M., Jacob. D. J. and Graustein, W. C. 1996. Vertical transport of aerosols in the troposphere as indicated by ${ }^{7} \mathrm{Be}$ and ${ }^{210} \mathrm{~Pb}$ and a chemical transport model. J. Geophys. Res. 101, 18,651-18,666.

Lambert, G., Polian, G., Sanak, J., Ardoiuin, B., Buisson, A., Jegou, A. and Leroulley, C. 1982. Cycle du radon et de ses descendants: application a l'etude des echanges troposphere-stratosphere. Ann. Glaciol. 38, 497-531.

Law, R., Simmonds, I. and Budd, W. F. 1992. Application of and atmospheric tracer model to the high southern latitides. Tellus 44B, 358-370.

Lee, H. N. and Feichter, J. 1995. An intercomparison of wet precipitation scavenging schemes and the emission rates of ${ }^{222} \mathrm{Rn}$ for the simulation of global transport and deposition of ${ }^{210} \mathrm{~Pb}$. J. Geophys. Res. 100, $23,253-23,270$.

Legates, D. R. and Willmott, C. J. 1990 Mean seasonal and spatial variability in gauge corrected global precipitation. Theoretical and Applied Climatology 41, 111-127.

Liu, S., McAfee, J. and Cicerone, R. 1984. Radon222 and tropospheric vertical transport. J. Geophys. Res. 89, 7291-7297.

Machenhauer, B. 1979. The spectral method. In: Numerical methods used in atmospheric models. GARP Publication Series no. 17, 121-275. World Meteorological Organization, Geneva, Switzerland.

Mahowald, N. M., Rasch, P. J., Eaton, B. E., Whittlestone, S. and Prinn, R. G. 1997. Transport of ${ }^{222}$ Radon to the remote troposphere using MATCH and assimil-

Tellus 52B (2000), 4 
ated winds from ECMWF and NCEP/NCAR. J. Geophys. Res. 102(D23), 28,139-28,152.

Manabe, S., Smagorinsky, J. and Strickler, R. F. 1965. Simulated climatology of a general circulation model with a hydrologic cycle. Mon. Weather Rev. 93, 769-798.

McNaughton, D. J. and Vet, R. J. 1996. Eulerian model evaluation field study (EMEFS): a summary of surface network measurements and data quality. Atmos. Environ. 30, 227-238.

Moore, H., Poet, S. and Martell, E. 1973. 222Rn, 210Pb, $210 \mathrm{Bi}$ and $210 \mathrm{Po}$ profiles and aerosol residence times versus altitude. J. Geophys. Res. 78, 7065-7075.

Polian, G., Lambert, G., Ardouin, B. and Jegou, A. 1986. Long-range transport of radon in subantarctic and antarctic areas. Tellus 38B, 178-189.

Prather, M. 1986. Numerical advection by conservation of second order moments. J. Geophys. Res. 91, 6671-6681.

Preiss, N. and Genthon, C. 1997. Use of a new database of lead 210 for global aerosol model validation. J. Geophys. Res. 102, 25,347-25,357.

Preiss, N., Melieres, M.-A. and Pourchet, M. 1996. A compilation of data on lead 210 concentration in surface air and fluxes at the air-surface and water-sediment interfaces. J. Geophys. Res. 101, 28,847-28,862.

Pyle, J. and Prather, M. 1996. Global tracer transport models, report of a scientific symposium. Bermuda, 1990 WMO/TD-no. 24, World Meteorological Organization, Geneva, Switzerland.

Rasch, P. J., Feichter, J., Law, K., Mahowald, N., Penner, J., Benkovitz, C., Genthon, C., Giannakopoulos, C., Kasibhatla, P., Koch, D., Levy, H., Maki, T., Prather, M., Roberts, D. L., Roelofs, G.-J., Stevenson, D., Stockwell, Z., Taguchi, S., Kritz, M. Chipperfield, M., Baldocchi, D., McMurry, P., Barrie, L., Balkanski, T, Chatfield, R., Kjellstrom, E., Lawrence, M., Lee, H. N., Lelieveld, J., Noone, K. J., Seinfeld, J., Stenchikov, G., Schwarz, S., Walcek, C. and Williamson, D. 1999. Tech. Rep. 29. WMO/ TD-no. 950, World Meteorological Organization, Geneva, Switzerland

Rasch, P. J. and Kristjánsson, J. E. 1998. A comparison of the CCM3 model climate using diagnosed and predicted condensate parameterizations. J. Clim. 11, 1587-1614.

Rasch, P. J. and Williamson, D. L. 1990. Computational aspects of moisture transport in global models of the atmosphere. Q. J. R. Meteorol. Soc. 116, 1071-1090.

Roeckner, E., Arpe, K., Bengtsson, L., Brinkop, S., Dümenil, L., Esch, M., Kirk, E., Lunkeit, F., Ponater, M., Rockel, B., Sausen, R., Schlese, U., Schuber, S. and Windelband, M. 1996. Simulation of the presentday climate with the ECHAM model: impact of model physics and resolution. MPI-Meteorology Publication 218, Max Planck Institute for Meteorology, Hamburg, Germany.

Roeckner, E., Arpe, K., Bengtsson, L., Claussen, M. C. M., Dümenil, L., Esch, M., Giorgetta, M. Schlese, U. and Schulzweida, U. 1992. The atmospheric general circulation model ECHAM-3: model description and sumulation of the present day climate. MPIMeteorology Publication 6, Max Planck Institute for Meteorology, Hamburg, Germany.

Schaug, J., Hansen, J. E., Nodop, K., Ottar, B. and Pacyna, J. M. 1987. Summary report from the chemical co-ordinating center for the third phase of EMEP. $E M E P / C C$-report $3 / 87$. Norwegian Institute for air research, Lillestrom, Norway.

Seinfeld, J. H. and Pandis, S. N. 1997. Atmospheric chemistry and physics. John Wiley \& Sons, New York, NY.

Taguchi, S. 1996. A three dimensional model of atmospheric $\mathrm{CO}_{2}$ transport based on analysed winds. J. Geophys. Res. 101 (D10), 15,099-15,109.

Thornton, D. C., Bandy, A. R., Blomquist, B. W. Driedger, A. R. and Wade, T. P. 1999. Sulfur dioxide distribution over the Pacific Ocean, 1991-1996. J. Geophys. Res. 104, 5845-5854.

Tiedtke, M. A. 1989. A comprehensive mass flux scheme for cumulus parameterization in large-scale models. Mon. Weather Rev. 117, 1779-1800.

Turekian, K. K., Nozaki, Y. and Benninger, L. 1977. Geochemistry of atmospheric radon and radon products. Ann. Rev. Earth Planet. Sci. 5, 227-255.

Wesely, M. L. 1989. Parameterization of surface resistances to gaseous dry deposition in regional scale numerical models. Atmos. Environ. 23, 1293-1304. 